\title{
Modeling the spatial distribution of larval fish abundance provides essential information for management
}

\section{Kallasvuo, Meri}

2017-05

Kallasvuo , M , Vanhatalo , J \& Veneranta , L 2017 , ' Modeling the spatial distribution of larval fish abundance provides essential information for management ' , Canadian Journal of

Fisheries and Aquatic Sciences , vol. 74 , no. 5 , pp. 636-649 . https://doi.org/10.1139/cjfas-2016-0008

http://hdl.handle.net/10138/193020

https://doi.org/10.1139/cjfas-2016-0008

other

acceptedVersion

Downloaded from Helda, University of Helsinki institutional repository.

This is an electronic reprint of the original article.

This reprint may differ from the original in pagination and typographic detail.

Please cite the original version. 
1 Accepted for publication in Canadian Journal of Fisheries and Aquatic Sciences, doi:

2 10.1139/cjfas-2016-0008:

3 http://www.nrcresearchpress.com/doi/abs/10.1139/cjfas-2016-0008\#.WDPddXrl-XC

4

6 Modeling the spatial distribution of larval fish abundance

7 provides essential information for management

8

9 Meri Kallasvuo ${ }^{1}$, Jarno Vanhatalo ${ }^{2,3}$, Lari Veneranta ${ }^{4}$

10

$11{ }^{1}$ Natural Resources Institute Finland (Luke), Bioproduction of Renewable Resources,

12 Viikinkaari 4, FI-00790 Helsinki, Finland, meri.kallasvuo@luke.fi

13 2Department of Mathematics and Statistics, University of Helsinki, Gustaf Hällströmin katu 2

14 B, P.O. Box 68, FI-00014 University of Helsinki, jarno.vanhatalo@ helsinki.fi

$15{ }^{3}$ Department of Biosciences, University of Helsinki, Viikinkaari 1, P.O. Box 65, FI-00014

16 University of Helsinki, jarno.vanhatalo@helsinki.fi

$17{ }^{4}$ Natural Resources Institute Finland (Luke), Bioproduction of Renewable Resources,

18 Korsholmanpuistikko 16, FI-65100 Vaasa, Finland, lari.veneranta@luke.fi

19

20 Corresponding author: 
21 Meri Kallasvuo, Natural Resources Institute Finland (Luke), Bioproduction of Renewable

22 Resources, Viikinkaari 4, FI-00790 Helsinki, Finland, +358295327070,

23 meri.kallasvuo@luke.fi 
24 Abstract

25

26 Productive fisheries are strongly linked to the ecological state of the essential habitats. In this

27 study, we developed a methodology to assess the most important reproduction habitats of fish

28 by using larval survey data and Bayesian species distribution models that predict the spatial

29 distribution and abundance of fish larvae. Our case study with four commercially and

30 ecologically important fish species in the coastal zone of the northern Baltic Sea

31 demonstrated that the production of fish stocks can be concentrated to an extremely limited

32 area compared to the entire suitable production area. The area suitable for larval production

33 varied from $3.7 \%$ to $99.8 \%$ between species, but the smallest area responsible for $80 \%$ of the

34 cumulative larval production was two to five times more limited, varying from $1.4 \%$ to

$3552.9 \%$ between species. Hence, instead of the traditional approach of modeling only habitat

36 suitability for fish production, marine spatial planning and management should take into

37 account the areal production potential. Moreover, the developed methodology enables linking

38 of the total production potential across the whole distribution area to fisheries stock

39 assessment and management. 
Introduction

The water areas that fish use for reproduction or as nurseries are referred to as essential fish habitats (Cross et al. 1997; Benaka 1999), since fish usually have the most specific habitat demands during spawning and early life-stages. Hence, the size of the reproduction habitats forms a habitat bottleneck that limits fish production (Halpern et al. 2005; Sundblad et al. 2014). Essential fish habitats often exist in shallow coastal areas (Seitz et al. 2014), which are also heavily exploited and threatened by various anthropogenic pressures (Seitz et al. 2014; Sundblad and Bergström 2014). Therefore, there is a growing need to find concrete tools to manage coastal areas effectively and plan multiple uses and conservation to ensure that coastal resources and services are utilized sustainably. During the last two decades, advances in marine habitat mapping and the development of geographic information system (GIS)-based tools for predicting species and habitat distributions (Guisan and Zimmermann 2000; Elith et al. 2006) have facilitated a detailed and explicit assessment of habitat availability. The main objectives in species distribution modeling are to predict the spatial and temporal occurrence or abundance pattern over a region of study and to identify the range of environmental covariates that best describe these patterns (Latimer et al. 2006; Austin 2007; Elith and Leathwick 2009). This information can also be used to predict species distributions under a changing environment.

Traditionally, species distribution models have focused on occurrence (Elith et al. 2006, Latimer et al. 2006). However, this approach fails to describe the abundance of a species, which may vary considerably between regions and habitats, and is essential information for management (Shelton et al. 2014; Thorson et al. 2015) and also for conservation purposes (Johnston et al. 2015). When abundance data, such as the number of 
64 individuals observed at a survey site, are available, it is possible to model the density of a species, i.e., the number of individuals within a given area (e.g. Vanhatalo et al., in press), or in the case of fish, in a given volume of water (e.g. Juntunen et al. 2012; Shelton et al. 2014; Thorson et al. 2015). The modeling outcome can then be presented as density maps that allow a comprehensive numerical evaluation of the species distribution and essential habitats. For example, those areas that are the most crucial for the total production of a fish stock can be identified.

In this study, we used a GIS- and modeling-based, spatially explicit approach to quantitatively assess the reproduction habitats of four commercially and ecologically important fish species in the northern Baltic Sea by predicting the distribution and abundance of their early life stages. We propose a novel approach to visualize and communicate the results to managers and other end-users by classifying areas based on their predicted contribution to the total production. As a result, we explicitly identify geographical areas that host the most productive coastal habitats and show that very limited coastal areas, compared to the total distribution area, can be crucial for fish production.

Materials and methods

Study species

83

The study considered four fish species that have both ecological and economic significance in the northern Baltic Sea area. The Baltic herring (Clupea harengus membras) is one of the most important pelagic species in the Baltic ecosystem and the most important species for fisheries in the northern Baltic Sea (Söderkultalahti 2015). The perch (Perca 
fluviatilis) and pikeperch (Sander lucioperca) are top predators and central species in the coastal system. They are fished commercially and are also highly sought after by recreational fishers (Söderkultalahti 2015). The smelt (Osmerus eperlanus) is a common species in estuarine areas (Shpilev et al. 2005), but nowadays mainly fished in the Gulf of Bothnia, the northernmost part of the Baltic Sea (Söderkultalahti 2015).

Three of the target species, the perch, pikeperch, and smelt, are of freshwater origin, and the Baltic herring is of marine origin. All the target species spawn in the spring in shallow $(<10 \mathrm{~m})$ coastal waters in the northern Baltic Sea (Aneer 1989; Lappalainen et al. 2003; Shpilev et al. 2005; Snickars et al. 2010). The two predatory species, perch and pikeperch, have specific habitat requirements for their reproduction, selecting shallow, vegetated, and sheltered bays that warm up early in the spring (Snickars et al. 2010; Veneranta et al. 2011). The smelt is perhaps even more selective and exclusively spawns in low salinity estuaries and river mouths (Urho et al. 1990; Shpilev et al. 2005). The perch, pikeperch, and smelt usually spawn in one reproductive cohort. The timing mostly depends on the development of spring temperatures (Lappalainen et al. 2003; Shpilev et al. 2005; Snickars et al. 2010; Veneranta et al. 2011). The Baltic herring is the most flexible of the studied species in its reproductive requirements, and spawns in several reproductive cohorts on both vegetation and hard bottoms in relatively low salinity coastal waters over the entire northern Baltic Sea (Aneer 1989; Parmanne et al. 1994). Despite some dissimilarity in their life history, the larvae of all four species use coastal habitats during their entire first summer (Sjöblom and Parmanne 1978; Urho and Hildén 1990; Sundblad et al. 2014).

Here, our main interest was in the early-stage larvae, which are found in the open water within the archipelago zone, usually still relatively close to the spawning sites, at approximately the same time of a year. It is not well known whether the larvae are only 
112 present in the surface water layer or more uniformly also in the deeper water layers.

113 However, in the spring, the water temperature is always highest near the surface, which

114 makes it the most favorable location for the larvae. Therefore, here we sampled fish larvae

115 only in the surface water layer.

116

117 Study area and data collection

118

119

The study area was located in the northern Baltic Sea, which is one of the

120 largest brackish semi-enclosed seas in the world. The coastal areas of the northern Baltic Sea

121 typically consist of extensive, shallow and topographically complex archipelagos, where the

122 coastline is indented and long, the sea is covered with ice in the winter months, and tides and

123 strong currents are absent (Voipio 1981). The study area covered the whole Finnish coastal

124 region (N 59.8-65.8, E 19.1-27.8) of $30100 \mathrm{~km}^{2}$ in the northern Baltic Sea (Fig. 1).

125 Environmental gradients are typically strong in the area, both north-south and west-east

126 along the coastline, and also from inshore to offshore (Kallasvuo 2010). For example, surface

127 salinity ranges from below 1 to almost $7 \mathrm{ppt}$ and the spring temperature varies strongly

128 between inner bays and open water areas.

To collect data on the distribution of the larvae of the four target species, an

130 extensive field survey of the surface water layer was conducted in 2007-2014 with paired

131 Gulf ichthyoplankton samplers, which have been used to quantitatively monitor the

132 abundance and spatial occurrence of, for example, Baltic herring larvae (Sjöblom and

133 Parmanne 1978; Parmanne and Sjöblom 1988; Urho and Hildén 1990) and pikeperch larvae

134 (Veneranta et al. 2011). The Gulf samplers, with a mouth opening of $0.028 \mathrm{~m}^{2}$, were attached

135 bilaterally to the bow of the boat. The sampling was systematically conducted during the day 
136 (8 am to $8 \mathrm{pm}$ ) over transects of $400 \mathrm{~m}$ (in 2007-2008) or $500 \mathrm{~m}$ (in 2009-2014) at a speed of

$1372.2 \mathrm{kn}$ and only in good weather conditions (wind speed $<8 \mathrm{~m} / \mathrm{s}$, wave height $<30 \mathrm{~cm}$ ). The

138 paired samplers had fixed depths of $0.5 \mathrm{~m}$ and $1.0 \mathrm{~m}$, and the catch and effort were pooled to

139 form one sample observation with a total effort (volume) of $22.68 \mathrm{~m}^{3}$ and $28.35 \mathrm{~m}^{3}$ per

140 shorter and longer transect, respectively. In 2014, at 18 very shallow, flad-type sampling

141 sites, Gulf sampling with a boat was not possible to conduct, and a similar net as in the Gulf

142 samplers was consequently used as a tow net. The tow net had a mouth opening of $0.166 \mathrm{~m}^{2}$

143 and it was hauled over five 30-m-long transects per flad. The catch and effort were pooled,

144 and the total sampling effort of one sample was $24.93 \mathrm{~m}^{3}$. These observations are a proxy

145 measure of larval abundance in units of count per effort, where the effort is the volume of

146 sampled water.

All samples were fixed in the field with $4 \%$ formaldehyde solution, and species

148 identification, counting, and measurement took place later in the laboratory. Since the aim

149 was to describe the distribution of the most sensitive reproduction habitats, not the larger

150 nursery areas, only early-stage larvae were included in the analysis. Our classification

151 followed that of Urho (1996; 2002), with a larval size range of 4-23 mm for perch, 5-15 mm

152 for pikeperch, and 4-36 mm for smelt. For Baltic herring, there is a known landward

153 movement and concentration of larger larvae in very shallow inner bay areas (Urho and

154 Hildén 1990), and we therefore used a more restrictive size range of 4-9 mm for Baltic

155 herring larvae. In 2007 in the Archipelago Sea, length measurements were not available for

156 Baltic herring larvae and the data from that year were not consequently used for the Baltic

157 herring model.

The larval fish survey comprised a total of 1788 sampling occasions at 655

159 distinct sampling sites in 5 sea areas (Fig. 1). Sampling sites were dispersed over the entire 
archipelago gradient, from the inner to the outer archipelago. In order to obtain survey results that were as representative as possible, the sampling was stratified according to bottom depth and exposure. Since different species hatch at different times, sampling was conducted two to four times per year at intervals of about 10-14 days at each site during a period from midMay to early July. In order to remove sampling occasions that were sampled before or after the larvae were present, we retained for each species only the sampling occasion with the largest larval abundance per sampling site and per year, which resulted in 655 observations of larval abundance per varying sampling effort. Each observation location was defined with coordinates corresponding to the start location of the sampling transect.

Spatial environmental data

173 falling into seven groups of covariates: depth, average depth, distance to deep water,

174 influence of rivers, shoreline density, exposure, and cumulative spring temperature

175 (summarized in detail in Table 1). The covariate depth corresponded to the actual depth at a point measured from the depth model at maximum resolution, while the covariate average

177 depth described the water depth gradient on a large spatial scale. The covariate distance to 178 deep water indicated the location in the archipelago zone, e.g. sheltered inner bays were 179 emphasized. The covariate influence of rivers described the influence of freshwater runoff 180 from the river mouths. The covariate shoreline density, i.e. length of the shoreline in meters in a grid cell, described the effect of wind exposure and water exchange, while the covariate exposure described the degree of wave exposure. The covariate cumulative spring 
temperature, i.e. the sum of daily sea surface temperatures from ice break up to July 15 th, described how rapidly the water area warmed up in the spring after ice break-up. The covariate GIS rasters were mainly constructed during this study by the authors, exceptions being depth, obtained from the Finnish Environment Institute (E. Virtanen, Finnish Environment Institute, Helsinki, personal communication, 2015), and exposure, which was obtained from AquaBiota Water Research (Isæus 2004). The influence of rivers and shoreline density were calculated based on basic maps (scale 1:5000, National Land Survey of Finland). The cumulative spring temperature was constructed by modeling the cumulative temperatures from survey loggers located in the study region and predicting the cumulative spring temperature for the entire study area (L. Veneranta, Natural Resources Institute Finland, Vaasa, personal communication, 2015). In order to enable spatial prediction, all covariates were in GIS raster format with the same extent and spatial resolution of $50 \mathrm{~m}$ and covered the whole geographical extent of the study area (see Fig. 1). The total number of grid cells across the study area was 12040 218. Covariate values were extracted for each observation from the grid cell in which that observation's starting point was located. Even though each transect passed through 7-12 grid cells, we did not expect this spatial misalignment to introduce large bias, since the environmental covariates were approximately constant along all transects at a sampling site. Most of the environmental variables were practically uncorrelated (the pairwise correlation in the data was less than 0.3 ), but there was greater correlation between the depth, average depth, and distance to deep water covariates (pairwise correlations ranged from 0.4 to 0.6 ) and between the influence of rivers and distance to deep water (pairwise correlation of 0.48). All GIS analyses were performed using the ESRI ArcGIS (ArcMap 10.2.1 and Spatial Analyst extension). 
Species distribution models

208

209

Traditional examples of species distribution models are generalized linear and

210

additive models (Guisan et al. 2002; Gelfand et al. 2006). Additionally, a wide variety of

211 other models have been proposed (e.g. Elith et al. 2006; Shelton et al. 2014; Thorson et al.

212 2015), and some of the most popular are non-parametric (Austin 2007; Elith et al. 2008).

213 Here, we built Bayesian species distribution models using Gaussian processes (GPs), as

214 proposed by Vanhatalo et al. (2012). GPs are stochastic processes that define the probability

215 distribution over functions and can be seen as an extension to linear and additive models

216 (Rasmussen 2004; Vanhatalo et al. 2012). They have received considerable interest in many

217 fields of science in recent years due to their semi-parametric nature, which allows flexible

218 and versatile modeling.

219

We modeled the conditional distribution for the number of larvae, $y(s, t)$, at

220

221

sample location $s$ (coordinates in kilometers) in year $t$ with a negative binomial distribution $y(s, t) \mid f(s, t), r \sim$ Negative $-\operatorname{Binomial}\left(z(s, t) e^{f\left(s, t, x_{s}\right)}, r\right)$,

222

where $z(s, t)$ is the corresponding sampling effort, the latent function $f\left(s, t, x_{s}\right)$ corresponds to the logarithm of the larval density, $x_{s}$ is the spatially indexed vector of $D$ covariates (see Table 1), and $r$ is the overdispersion parameter. We parameterized the negative binomial as in Vanhatalo et al. (2013) with a quadratic mean-variance relationship so that mean $E[y(s, t)]=z(s, t) e^{f\left(s, t, x_{s}\right)}$ and variance $\operatorname{Var}[y(s, t)]=E[y(s, t)]+E[y(s, t)]^{2} / r$. Hence, increasing $r$ corresponds to decreasing variance, and at the limit, as $r$ approaches infinity, the negative binomial approaches a Poisson distribution. Before modeling, we scaled all the covariates to have a unit standard deviation and zero mean according to the observed values. 

density, since our model does not account for the catchability of the used sampling gear, and

232 it represents the expected (average) number of larvae per cubic meter of water at a particular

233 location and time. The catchability of our sampling gear was mostly influenced by the

234 weather conditions during the sampling occasions. Special attention was paid to standardizing these conditions as well as possible, and there were no systematic variations in the sampling conditions between different areas (see also Study area and data collection section). Hence, it is reasonable to assume that catchability did not vary systematically. However, due to random variation in the sampling conditions, there might still be random variation in catchability. In addition to other sources of extra variation, the spatial and spatio-temporal random effects account for spatially correlated and the overdispersion in negative-binomial distribution for uncorrelated variation in catchability. Overdispersion may arise from various factors in addition to the variation in catchability, including a spatially aggregated distribution of individuals (Lindén and Mäntyniemi 2011).

We assumed that the latent function is additive so that

$$
f\left(s, t, x_{s}\right)=\alpha+\sum_{d=1}^{D} g_{d}\left(x_{s, d}\right)+h\left(x_{s}\right)+\rho(s)+\phi(s, t)
$$

Here, $\alpha$ is the intercept, $g_{d}(\cdot)$ is a univariate function of the $d^{\text {th }}$ covariate, $h\left(x_{s}\right)$ is a function

247 of interactions between all the covariates, $\rho(s)$ is a spatial random effect, and $\phi(s, t)$ is a spatio-temporal random effect. Hence, the model is essentially a generalized additive model with random effects (Hastie and Tibshirani 1990) and the motivation for the chosen model structure is the following. The intercept describes the average density of larvae across the

251 study area. The univariate function, $g_{d}(\cdot)$, corresponds to the independent effect of a covariate $d$ and, hence, describes the average relative change in density with respect to that covariate across the whole study area. The function of interactions governs the joint effect of 
all the covariates. The lower order interactions were left out in order to reduce the complexity of the model (see e.g. Plate 1999). This choice was justified, since it was a priori likely that the independent effects would be stronger than interactions, and because our prior for $h\left(x_{s}\right)$ shrinks the effects of covariates towards zero if the data do not support the full order of interactions. The spatial random effect captures spatial autocorrelation, which causes neighboring areas to have similar larval densities because of, for example, associations unexplained by the available covariates (Latimer et al. 2006; Elith and Leathwick 2009).

Similarly, the spatio-temporal random effect adjusts for annual variation in density that cannot be described by the temporally constant covariates.

Following Vanhatalo et al. (2012), we gave a Gaussian prior for the intercept $\alpha \sim N\left(0, \sigma_{\alpha}^{2}\right)$ and Gaussian process (GP) priors for all the latent functions

GP is a stochastic process that defines the probability distribution over functions (Gelfand et al. 2010; Rasmussen and Williams 2006). It is defined by a mean function, here zero, and a covariance function, e.g., $k_{g_{d}}\left(x_{s, d}, x_{s^{\prime}, d}\right)=\operatorname{Cov}\left(g_{d}\left(x_{s, d}\right), g_{d}\left(x_{s^{\prime}, d}\right)\right)$, which determines the 272 properties of the process, such as how much and how fast (smoothness) the function varies 273 along a covariate. Here, $x_{s, d}$ and $x_{s^{\prime}, d}$ are the $d^{\text {th }}$ covariate at locations $s$ and $s^{\prime}$, respectively. We used the neural network covariance function for each univariate function, 
2006), where $\tilde{x}_{s, d}=\left[1, x_{s, d}\right]$ and $\theta_{g_{d}}=\operatorname{diag}\left(\sigma_{g_{d}, 0}^{2}, \sigma_{g_{d}}^{2}\right)$. The parameters $\sigma_{g_{d}}^{2}$ and $\sigma_{g_{d}, 0}^{2}$

277 respectively govern how smooth the function is along $x_{d}$ and its offset from zero, so that the

278 larger the variance parameters are, the more quickly the function varies. The neural network covariance function gives rise to non-linear and non-stationary random processes whose expected value outside the data range stabilizes (approximately) to the level at which it was at the end of the data range (Vanhatalo et al. 2012). These properties are justified, since it was $a$ priori likely that abundance responds to covariates non-linearly, and due to the sampling design, the density is not expected to change radically from the level at the end of the data range when moving outside the data range.

The interactions between covariates were modeled by giving $h\left(x_{s}\right)$ a squared exponential covariance function $k_{h}\left(x_{s, d}, x_{s^{\prime}, d} \mid \theta_{\mathrm{h}}\right)=\sigma_{h}^{2} e^{-\sum_{d=1}^{D} w_{d}^{2}\left(x_{s, d}-x_{s^{\prime}, d}\right)^{2} / 2}$, where $\theta_{\mathrm{h}}=$ $\left[\sigma_{h}^{2}, w_{1}, \ldots, w_{D}\right], w_{d}$ is the weight (inverse length scale; Rasmussen and Williams 2006) along covariate $d$ and $\sigma_{h}^{2}$ is the process variance (magnitude). The weight governs how fast the function varies along $x_{s, d}$ and hence its effect in the interaction term. The effect of a covariate in the interaction term vanishes when the respective weight approaches zero. The magnitude governs the importance of the interaction term relative to other terms. $k_{\rho}\left(s, s^{\prime}\right)=\sigma_{\rho}^{2} \mathrm{e}^{-\sqrt{\sum_{i=1}^{2}\left(s_{i}-s^{\prime} i^{2} / \lambda_{i}^{2}\right.}}$, and for the spatio-temporal random effect we used a separable covariance function with an exponential form for both the space and the time 295 components, so that $k_{\phi}\left((s, t),\left(s^{\prime}, t^{\prime}\right)\right)=\sigma_{\phi}^{2} \mathrm{e}^{-\sqrt{\sum_{i=1}^{2}\left(s_{i}-s^{\prime}\right)^{2} / l_{i}^{2}}} \mathrm{e}^{-\left|t-t^{\prime}\right| / l_{3}}$. The length-scale parameters govern the autocorrelation length of the GP along longitude $\left(\lambda_{1}, l_{1}\right)$, latitude $\left(\lambda_{2}\right.$, $l_{2}$ ) and time $\left(l_{3}\right)$, so that the correlation between two locations drops below $5 \%$ of its maximum when these locations are further than approximately three times the length scale 
apart. The variance parameters $\sigma_{\rho}^{2}$ and $\sigma_{\phi}^{2}$ govern the magnitude of the process variation. The

300 exponential covariance function leads to a stationary process in time and space, and is a

301 common choice when modeling spatial processes (Gelfand et al. 2010).

302

We used log-uniform priors for the variance parameters $\sigma_{\rho}^{2}, \sigma_{\phi}^{2}, \sigma_{h}^{2}$ and

$303\left\{\sigma_{g_{d}, 0}^{2}, \sigma_{g_{d}}^{2}\right\}_{d=1}^{D}$ and weakly informative half Student- $t$ priors (Gelman 2006) for the other

304 hyper-parameters. For weights $w_{d}$ and the temporal length scale, $l_{3}$, we used four degrees of

305 freedom and scale one in the half Student- $t$ prior, and for the spatial length scales $\lambda_{1}, \lambda_{1}, l_{1}$,

$306 l_{2}$ we used four degrees of freedom and scale 100. All the priors are summarized in Table 2.

307 Since the chosen priors have most of their mass near zero, they favor rigid functional forms

308 (that is, functions that vary slowly along the covariates) with a low order of interactions and a

309 short autocorrelation length in the random effects. We conducted a sensitivity test for the

310 priors by increasing the scale of the half Student- $t$ priors by ten-fold and could conclude that

311 the results were not sensitive to the chosen priors.

312

313 Inference, prediction, and model assessment

314

We built and inferred one model for each of the four target species. We applied

316 Bayes' theorem and calculated the posterior distribution of all model parameters and latent

317 functions using the expectation propagation and Markov chain Monte Carlo algorithms

318 implemented in the Matlab toolbox GPstuff (Vanhatalo et al. 2013; Appendix A1) ${ }^{1}$. We

319 conducted convergence diagnostics for the Markov chains and used the posterior predictive

320 check (Gelman et al. 2013) for model validation by simulating replicate measurements from

${ }^{1}$ The code to implement the models is given in the Supplementary material. 
321 the posterior predictive distribution of each model and compared the samples with the

322 measured data. We also assessed the importance of the spatial and spatio-temporal random

323 effects by comparing our model with similar models without the random effects. See

324 Appendix A1 for details.

The full set of environmental covariates fell into seven groups of covariates that

were a priori potentially good proxies for the essential environmental characteristics of the reproduction habitats. Three of the groups contained several similar covariates at varying spatial scales (Table 1). For example, varying the diameter from $3 \mathrm{~km}$ to $15 \mathrm{~km}$ for the circles in which the shoreline density was calculated corresponded to a change from a local to a more global shoreline density index. On the other hand, changing from the distance to $10-\mathrm{m}-$ deep water to the distance to 30-m-deep water changed the focus from shallow waters to deeper waters, since in the coastal region of the northern Baltic Sea, the distance from 10-mdeep to 30-m-deep waters may be so large that the latter is not descriptive in the shallowest regions. For each species, we selected the best environmental covariate from each of the groups of covariates according to the leave-one-out cross-validated log predictive density

336 (Vehtari and Ojanen 2012). The final analyses were conducted with the reduced covariate set, which made the interpretation of the results easier. distribution of the latent function $f\left(s, t, x_{s}\right)$ and, hence, larval density in the surface water

340 layer of all grid cells in the entire study area. Since we had the spatio-temporal component in 341 our model, we predicted the mean density over the survey years as detailed in Appendix A1.

342 For each species, we present the larval density and its coefficient of variation over the study

343 area. We also approximated the total number of larvae in the surface water layer per sea area 344 and across the whole study area from the sum of the predictive densities in grid cells in an 
area multiplied by the water volume of the surface water layer up to the depth of $1.5 \mathrm{~m}$ in a

346 grid cell (i.e., $1.5 \times 50 \times 50 \mathrm{~m}^{3}$ ). Since we had over 12 million grid cells in the whole study

347 area, we needed to approximate the posterior distribution of the sum as described in

348 Appendix A1.

In order to study the relative importance of different parts of the study area for

350 fish reproduction, we classified the total area into not suitable, suitable, and important areas.

351 Each grid cell was classified as not suitable if the expected probability for zero observations

352 in a sample of three transects (the average number of transects per sample) was more than

$35350 \%$. This limit corresponds to using an occurrence model to classify areas as not suitable

354 based on a 50\% cut-off value. Next, in order to emphasize the most important fish

355 reproduction areas, we further divided the remaining grid cells into two classes. The important grid cells are those that were in the smallest subset of grid cells whose expected cumulative number of larvae was $80 \%$ of the total expected number of larvae in all grid cells that had a presence probability of $50 \%$ or more. The rest of the grid cells were classified as suitable. The rationale for this division is the following. Knowledge of potential species reproduction areas (areas with 50\% or more probability of larval presence) is necessary for coastal spatial planning and management. However, it is not sufficient information for efficient management, since the larval density in these areas may vary considerably, and the importance of these areas for reproduction at the population level may thus range from very

364 low to very high. Hence, the expected number of larvae produced by an area provides a more

365 informative summary for management, since it is directly related to that area's expected 366 utility for fish production. Here, we chose the cut-off value for demonstrative purposes, and

367 other values could be more justified in specific management applications. 

along individual covariates may vary across locations (Vanhatalo et al. 2012). Hence, in order to examine the effect of covariates on larval density, we visualized the expected, zerocentered change in the log density along each covariate and variation in it over the training

372 data locations. See Appendix A1 for details.

374 Results

Model assessment and posterior inference

All models performed well according to the posterior predictive checks. Table 3 summarizes the posterior distribution of the spatial random effects, the overdispersion parameter, and the variance of the interaction term. The posterior mean of the intercept term corresponded to an average of $2.3 \times 10^{-2}$ larvae per $\mathrm{m}^{3}$ for perch, $1.4 \times 10^{-3}$ larvae per $\mathrm{m}^{3}$ for

382 pikeperch, $6.3 \times 10^{-2}$ larvae per $\mathrm{m}^{3}$ for Baltic herring, and $3.6 \times 10^{-2}$ larvae per $\mathrm{m}^{3}$ for smelt.

383 In perch, herring, and smelt models, there was clear overdispersion compared to a standard

384 Poisson model. In the pikeperch model, the overdispersion parameter was higher, but on the 385 other hand, the length scales of the spatio-temporal random effect in this model were considerably smaller than in other models. As the length scales approach zero, this random

387 effect approaches spatially independent overdispersion and takes essentially the same role as

388 the overdispersion parameter. According to the spatial length scales, the spatial autocorrelation in the random effects vanished in tens of kilometers. Hence, compared to the scale of the whole modeled area, the random effects described local corrections to density

391 predictions made by the covariates only. According to the temporal length scales of the 
spatio-temporal random effects, the spatio-temporal correlations dropped to approximately $20 \%$ of their maximum between consecutive years and practically to zero correlation after two years. Hence, there were no temporal trends in larval abundances.

According to the cross-validation tests, the models worked significantly better than otherwise similar models without any random effects and practically as well as or better than otherwise similar models only having either one of the random effects. Moreover, once random effects were dropped from a model, its overdispersion parameter tended to decrease, which indicates that (part of) the variation captured by the random effects was then transferred to the overdispersion. See Appendix A1 for the comparison results.

Figure 2 shows the posterior predictive response of log density along environmental covariates for each species. All the responses were mostly additive, since there was only moderate variation in the responses across the study region. A change in log density by one unit corresponded to a 2.7-fold increase in the density. Hence, the most significant covariate effects, with a change in $\log$ density by $3-4$ units, corresponded to a $20-50$-fold increase in the larval density. The responses of larval densities along environmental covariates varied between the species. Perch had negative responses to an increasing depth, average depth and exposure and positive responses to an increasing distance to deep water $(10 \mathrm{~m})$, the influence of rivers, and the cumulative spring temperature. Pikeperch had strong negative responses to an increasing average depth, shoreline density, and exposure, and strong positive responses to an increasing distance to deep water $(10 \mathrm{~m})$ and the cumulative spring temperature. Baltic herring had a negative response to the distance to deep water (20 m) and strong positive responses to an increasing average depth, shoreline density, and exposure. The response of Baltic herring to an increasing cumulative spring temperature was positive, with a peak at 1200 day-degrees, and at higher cumulative temperatures it turned 
negative. Smelt had strong negative responses to an increasing average depth, negative

417 responses to shoreline density and exposure, and positive responses to an increasing distance to deep water $(30 \mathrm{~m})$, the influence of rivers, and the cumulative spring temperature.

420 Larval density predictions

Larval habitats for pikeperch, perch, and smelt were characterized as shallow, sheltered and, thus, areas that warmed relatively rapidly, which were most often found in the

424 inner archipelago, frequently close to river mouths. A somewhat opposite pattern was typical 425 for Baltic herring larval habitats, which were characterized as more exposed areas with a 426 lower cumulative spring temperature compared to other studied species (Figs 2 and 3 ).

427 Pikeperch had the most and the Baltic herring the least limited environmental requirements of the studied species, concerning the environmental covariates used here.

Figure 3 illustrates the predicted larval density classified into three classes: not

430 suitable, suitable and important. Figure 4 summarizes the posterior predictive median and 431 coefficient of variation of the larval density, and Table 4 summarizes the total number of 432 larvae and areas suitable for reproduction across the study region and the five sea areas.

433 Baltic herring had the highest predicted total number of larvae of the target species in the 434 studied area; the predicted total number of larvae as a percentage of the total number of Baltic 435 Herring larvae was $17.9 \%$ for perch, $6.2 \%$ for pikeperch, and $67.8 \%$ for smelt. The total area 436 suitable for larval production was largest for Baltic herring, covering $99.8 \%$ of the studied 437 coastal area. The most limited larval production area (3.7\%) was recorded for pikeperch. The 438 proportion of the studied coastal area suitable for larval production was $13.7 \%$ for perch and $43922.5 \%$ for smelt. There was, however, variation in the species-specific distribution of larval 
440 production areas between the five studied sea areas (Table 4); larval production areas for

441 perch and smelt were proportionally larger in the northern parts of the study area (I-III for

442 perch, I for smelt), whereas larval production areas for pikeperch and Baltic herring were

443 proportionally larger in the southern parts of the study area (IV-V).

The important habitats (those that accounted for $80 \%$ of larval production) were more limited than the suitable larval habitats, comprising $3.0 \%$ of the studied sea area for perch, $1.4 \%$ for pikeperch, $52.9 \%$ for Baltic herring, and $4.4 \%$ for smelt (Table 4). The spatial focus of the important habitats also varied, reflecting the same south-northward pattern seen for the total larval production areas (Fig. 3).

Discussion demonstrated that very limited coastal areas can be crucial for fish reproduction. The availability of suitable larval reproduction habitats is not necessarily a good indicator of important fish reproduction areas, since some suitable habitats may contribute orders of magnitude more to the total larval production than others. Therefore, abundance models should be preferred over occurrence models when studying the reproduction habitats of fish and their quality and impact on total fish production. Our results support the recent findings

460 of Johnston et al. (2015) that abundance models are more accurate and thus preferable for both aggregated and non-aggregated species. 
are fundamentally important in order to quantify the interpretation of the maps, prevent

465 misunderstanding, and enable the comparison and value judgment of different coastal sea

466 areas for larval fish production. Visualizing maps, as proposed in this work, very clearly

467 show that the most productive larval habitats can be very limited compared to the entire

468 suitable reproduction habitats of a species; the areas expected to produce $80 \%$ of the species-

469 specific larval production (important areas) were two to five times more limited than the

470 entire larval production areas (suitable areas), and varied between species from $1.4 \%$ to

$47152.9 \%$ of the total study area. This information should be taken into account when planning

472 management and conservation measures. However, the $80 \%$ cut-off level in this work was

473 chosen for demonstrative purposes and, depending on a species, another level could be more

474 justified. For example, when analyzing healthy and balanced fish stocks that allow for

475 exploitation without risk of stock depletion, a lower cut-off level ( $<80 \%$ of the cumulative

476 larval production) could be enough to present the assumedly extensive larval production

477 habitats. On the other hand, some endangered fish stocks could demand a much higher cut-off

478 level (>80\% of the cumulative larval production) in order to apply a precautionary approach

479 when focusing conservation acts. Hence, the cut-off level for the important reproduction

480 areas should ideally be chosen in parallel with stock assessment and reflect the management

481 and conservation objectives. Moreover, in some applications, we could be interested in a

482 more precautionary summary than the expected number of larvae. For example, the important

483 area could have a cut-off value ensuring that the total number of larvae in that area is greater

484 than a certain percentage of the total number of larvae in the whole study area with a

485 probability greater than, for example, 0.9 .

We found large differences in the spatial larval habitat distribution between the

487 four studied fish species. The response of Baltic herring to environmental covariates, i.e. 
environmental requirements, was the least limited of the studied species, and its larval production area was the widest. The pikeperch, on the other hand, is an example of a species with very strict environmental requirements in the reproductive stage (Sundblad et al. 2014; Veneranta et al. 2011), and its total reproduction area was accordingly the most limited. The specific ecological habitat requirements of each species were also reflected in the responses of larval densities to the environmental covariates chosen for the species-specific models. For example, both pikeperch and perch larvae were most abundant in areas that had a high cumulative spring temperature, which supports the finding that the year-class strength of both pikeperch and perch is known to largely depend on temperature (Kjellman et al. 2003; Pekcan-Hekim et al. 2011; Lehtonen et al. 1996). Moreover, the covariates chosen for the pikeperch model describe very local aspects in the inner archipelago, whereas the covariates chosen for the herring model describe broader and more pelagic aspects. Overall, the results emphasized the importance of the shallow parts of the coastal area, but when interpreting the results one has to keep in mind that the field survey was only conducted in the surface water 502 layer. our results. This was expected, since it has the highest stock size of the studied species and is the most important species for fisheries in the northern Baltic Sea (Söderkultalahti 2015). The Baltic herring is a pelagic species that is known to reproduce over a large area and during a

507 time period of several months in spring and early summer (Parmanne et al. 1994; Fey 2001;

508 Hakala et al. 2003). Perch, pikeperch, and smelt, on the other hand, are strictly coastal species with specific and rather similar reproductive requirements and a reproductive period of some weeks (Snickars et al. 2010; Sundblad et al. 2014). Therefore, the suitability of the used field survey and modeling methods probably varied between species. Firstly, sampling should 
512 optimally have been carried out during the whole summer in order to cover several

513 reproductive cohorts and enable modeling of the length of the reproduction season for each

514 species. However, this was not feasible in our survey program, and our model does not

515 therefore take into account the lengths of the reproductive seasons nor the number of cohorts;

516 hence, the total numbers of larvae represent the numbers of larvae produced by those cohorts

517 that our survey covered during the reproduction season. Secondly, only the surface water

518 layer was sampled and modeled here. Larval perch, pikeperch, and smelt are known to be

519 abundant in the surface water layer (Urho et al. 1990), but Baltic herring larvae are also found

520 in deeper water layers (Sjöblom and Parmanne 1978). Therefore, the model should have

521 taken into account the entire water layer in which larvae are present in order to compare the

522 total numbers of larvae between species. Since our sampling did not provide information on

523 the distribution depth, we restricted our study to the surface water layer and assumed that the

524 distribution depth does not differ significantly between areas. According to earlier studies

525 (Parmanne and Sjöblom 1988), this assumption is reasonable. Thirdly, our model did not

526 explicitly account for variation in catchability, but the modeled density accounted for both

527 catchability and the total abundance of larvae. Hence, systematically varying catchability

528 would introduce bias in our density estimates. However, we do not expect the catchability to

529 have varied systematically between areas, since the weather conditions during the surveys

530 were standardized as well as practically possible. Moreover, the catchability was not expected

531 to differ significantly between pikeperch, perch, and smelt. However, according to the

532 posterior distributions of spatial and spatio-temporal random effects and the overdispersion

533 parameter, the overdispersion compared to the expected density (that is, extra uncertainty)

534 was significant for all species. This overdispersion is expected to partly arise from varying

535 catchability due to weather and other sampling conditions. Therefore, the results presented 
here are most robust when examining regional differences in species-specific distribution areas and densities and, unfortunately, the quantitative comparison of the total number of larvae between the studied species is only indicative between perch, pikeperch, and smelt and not possible between herring and other species. It is also important to keep in mind that we sampled early-stage fish larvae, which still have many bottlenecks to survive before they recruit to the adult population (Miller et al. 1988; Myers 1998). The distribution of species-specific reproduction habitats and species

543 abundances are not static over time, and temporal changes may reduce the long-term

544 generality of the habitat and abundance predictions. Matching the field sampling with the 545 occurrence of early-stage larvae is also challenging, producing uncertainty in the probability

546 of detection. Moreover, constructing good environmental covariates is difficult, and GIS-

547 based environmental covariates can never encode all essential abiotic aspects related to 548 species distributions (Elith et al. 2006). We have addressed these challenges in both the data 549 collection and modeling. The temporal fluctuations were accounted for by using field survey 550 data from multiple years (2007-2014), which allowed us to model the average distribution of 551 reproduction habitats and the average density over those years. The sampling was performed multiple times each year so that the probability of matching it with the presence of earlystage larvae was increased. In constructing the environmental covariates, we used only

554 general environmental descriptors such as depth to increase the generality of the predictions, 555 as suggested by Sundblad et al. (2014), among others. The annual fluctuations and possible 556 time mismatch in sampling were also explicitly modeled by the spatio-temporal random 557 effects component. Moreover, we included the spatial random effect in our model to account 558 for static patterns in data that were not explained by our covariates. According to the results, 559 the random effects improved the model performance compared to otherwise similar models 
without the random effects (see Appendix A1). Hence, the inclusion of the random effects was justified. If a priori justified, we could also model multiple spatial processes at different scales with a different choice of the covariance functions, such as an additive covariance function with short and long length scales (Vanhatalo and Vehtari 2008). structure of the predictive model for the covariates (Vanhatalo et al. 2012). Here, we used an additive structure that included non-linear univariate terms and a function with interactions.

We used neural-network covariance functions for the univariate terms, since they were shown to work well in extrapolation by Vanhatalo et al. (2012). The squared exponential covariance

569 function, on the other hand, is a standard choice to model full interactions (see e.g.

570 Rasmussen and Williams 2006). Our choice of covariance functions proved to be justified 571 here, since all the responses were non-linear and the interactions were rather weak. The models also performed well in the posterior predictive checks. However, the interpolation and extrapolation behavior of a GP depend on the chosen covariance function (Vanhatalo et al.,

574 2012). Some covariance functions, such as the commonly used squared exponential, behave

575 similarly to splines (which are often used in generalized additive models) so that they 576 typically perform well when predicting within the data range (interpolation). However, when 577 extrapolating the prediction outside the data range, the result may be unfavorable, since 578 predictions approach the prior mean (that is, zero). The neural network covariance function 579 works differently by allowing non-linear responses and extrapolations that follow the level at 580 which the predictive function is at the end of the data (see Appendix A1 and Figure A1).

581 However, if we had strong prior knowledge on the likely response, we could describe this with a parametric function, such as a linear, bell shaped or, for instance, Michaelis-Menten

583 functional form (Vanhatalo et al., in press) and use GPs to model possible discrepancies from 
584

585

586

587

588

589

590

591

592

593

594

595

596

597

598

599

600

601

602

603

604

605

606

607

this parametric form. We chose the environmental variables based on their biological justification and did not transform them in order to remove collinearity, because such transformations would obscure the interpretation of the responses. Collinearity is not a problem when predicting the larval distribution. Compared to prediction with one covariate, in case of strong collinearity between two or more covariates, the predictive contribution is simply divided between the correlated covariates. However, as in (generalized) linear and additive models, collinearity is a challenge when inferring the responses along covariates. In order to remedy this, the hyperparameters of the predictive functions were given weakly informative priors, which prefer constant functions. Hence, in the case of strong collinearity, the response along the "weaker" covariates will be shrunk towards zero, whereas the covariates that explain data better should have a stronger response (see also Simpson et al. 2015 for a more general discussion on penalized complexity priors). However, our prior structure did not strictly promote sparsity, and theoretically or empirically justified general rules for choosing the covariance functions for the predictive GP models and priors for their hyperparameters still provide room for future research.

The methods presented here provide concrete support for environmental management and the spatial planning of coastal and marine areas by providing a means to prioritize areas with a high production potential (abundance) over areas that are suitable for reproduction but do not significantly contribute to larval production. For example, the results presented here aid in the implementation of the EU Maritime Spatial Planning directive and local dredging permission procedures in Finland to focus on the most important areas from the perspective of larval production. Fisheries stock assessment and management could also benefit from this type of approach, since the results for larval abundance could be used to describe the reproductive potential of a fish stock, as has been conducted for Baltic Salmon 
608 (Kuikka et al. 2014), which would not be possible with presence/absence models. Regarding their short-term utilization, the results of this study will help in the implementation of the new

610 Finnish Fishing Act (enacted on January $1^{\text {st }}, 2016$ ) which involves changes in the spatial

611 organization of fisheries management in terms of utilization and conservation planning. The

612 implementation of the new law requires detailed information, among others, on fish

613 production areas. Moreover, scientific knowledge of the distribution of fish stocks and

614 important production areas is needed to inform policy makers about the best sustainable

615 management practices and to assess the current fisheries management policies in general.

616 Habitat protection is a strategy often proposed in fisheries and environmental

617 management to help maintain viable populations of exploited or endangered species. Besides

618 habitat quality, habitat connectivity is also considered an important characteristic in the

619 protection of essential coastal habitats (Halpern et al. 2005; Lipcius et al. 2008). In this study,

620 we have shown that species distribution models providing high-resolution predictions for

621 larval density on a geographically wide scale can be used to numerically compare and value

622 different sea areas for larval fish production, and therefore provide easy-to-interpret maps for

623 management and coastal and marine spatial planning purposes. Sundblad et al. (2014) have

624 suggested that a substantial proportion of the potential production of adult fish can be

625 estimated by mapping the distribution of essential fish habitats, since habitat bottlenecks in

626 the early life-stages limit the abundance of later adult stages of predatory fish. Here, we

627 showed that the production of fish stocks can be concentrated in spatially extremely limited

628 areas compared to the suitable production areas. Hence, the total production potential

629 (abundance) of an area should be taken into account in, for example, marine spatial planning.

630 Future efforts should focus on linking this modeling and mapping approach to catches to 
631

632

633

634

635

636

637

638

639

640

641

642

643

644

645

646

647

648

649

650

651

652

653

654

study the link between essential habitats and stock assessment of the most important coastal commercial fish species.

Acknowledgements

The authors thank the field staff of Luke who took part in the extensive larval

fish survey and Prof. Sakari Kuikka, Dr Antti Lappalainen, Dr Mika Rahikainen, and two anonymous reviewers for valuable comments on the manuscript. The authors also thank Elina

Virtanen from the Finnish Inventory Programme for Marine Underwater Environment

(VELMU), the Finnish Environment Institute (Syke), for providing the depth data. Meri

Kallasvuo and Lari Veneranta were funded by the Ministry of Agriculture and Forestry

Finland / VELMU programme (2502/311/2012) and by the Strategic Research Council of the

Academy of Finland / SmartSea (grant 292985). Jarno Vanhatalo was funded by the

Academy of Finland (grants 266349 and 292985) and Research Funds of the University of Helsinki.

References

Aneer, G. 1989. Herring (Clupea harengus L.) spawning and spawning ground characteristics in the Baltic sea. Fish. Res. 8: 169-195.

Austin, M. 2007. Species distribution models and ecological theory: A critical assessment and some possible new approaches. Ecol. Model. 200: 1-19.

Benaka, L. 1999. Fish habitat: Essential fish habitat and rehabilitation. American Fisheries Society, Symposium 22, Connecticut. 
655 Cross, J.N., Brown, D.W., and Kurland, J.M. 1997. Essential fish habitat: A new fisheries

656

657

658

659

660

661

662

663

664

665

666

667

668

669

670

671

672

673

674

675

676

677

678 management tool. ICES council meeting papers, Copenhagen, Denmark.

Elith, J., and Leathwick, J.R. 2009. Species distribution models: Ecological explanation and prediction across space and time. Annu. Rev. Ecol. Evol. Syst. 40: 677-697. doi:

http://www.annualreviews.org/doi/abs/10.1146/annurev.ecolsys.110308.120159

Elith, J., Graham, C.H., Anderson, R.P., Dudik, M., Ferrier, S., Guisan, A., Hijmans, R.J., Huettmann, F., Leathwick, J.R., Lehmann, A., Li, J., Lohmann, L.G., Loiselle, B.A., Manion, G., Moritz, C., Nakamura, M., Nakazawa, Y., Overton, J.M.C., Peterson, A.T., Phillips, S.J., Richardson, K., Scachetti-Pereira, R., Schapire, R.E., Soberon, J., Williams, S., Wisz, M.S., and Zimmermann, N.E. 2006. Novel methods improve prediction of species' distributions from occurrence data. Ecography 29(2): 129-151. doi: 10.1111/j.2006.0906-7590.04596.x.

Elith, J., Leathwick, J.R., and Hastie, T.R. 2008. A working guide to boosted regression trees. J. Anim. Ecol. 77: 802-813. doi: 10.1111/j.1365-2656.2008.01390.x.

Fey, D.P. 2001. Differences in temperature conditions and somatic growth rate of larval and early juvenile spring-spawned herring from the vistula lagoon, Baltic Sea manifested in the otolith to fish size relationship. J. Fish. Biol. 58: 1257-1273.

Gelfand, A.E., Holder, M., Latimer, A., Lewis, P.A., Rebelo, A., Silander, J.A., and Wu, S. 2006. Explaining species distribution patterns through hierarchical modeling. Bayesian Anal. 1: 41-92.

Gelfand, A., Diggle, P.J., Fuentes, M., and Guttorp, P. 2010. Handbook of spatial statistics. CRC press, Miami, USA. 
679 Gelman, A. 2006. Prior distributions for variance parameters in hierarchical models.

680 Bayesian Anal. 1(3): 515-533.

681 Gelman, A., Carlin, J., Stern, H., Dunson, D., Vehtari, A., and Rubin, D. 2013. Bayesian data 682 analysis, third edition. Chapman \& Hall / CRC Texts in Statistical Science, Miami, USA.

684

Guisan, A., and Zimmermann, N.E. 2000. Predictive habitat distribution models in ecology. 685 Ecol. Model. 135(2-3): 147-186.

686

Guisan, A., Edwards Jr, T.C., and Hastie, T. 2002. Generalized linear and generalized 687 additive models in studies of species distributions: Setting the scene. Ecol.

688 Model. 157(2): 89-100. doi: http://dx.doi.org/10.1016/S0304-3800(02)00204-1.

Hakala, T., Viitasalo, M., Rita, H., Aro, E., Flinkman, J., and Vuorinen, I. 2003. Temporal 690 and spatial variation in the growth rates of Baltic herring (Clupea harengus

691 membras L.) larvae during summer. Mar. Biol. 142(1): 25-33. doi:

692 10.1007/s00227-002-0933-3.

Halpern, B.S., Gaines, S.D., and Warner, R.R. 2005. Habitat size, recruitment, and longevity 694 as factors limiting population size in stage-structured species. Am. Nat. 165(1):

695 82-94.

696

Hastie, T., and Tibshirani, R. 1990. Generalized additive models. Chapman and Hall, 697 London.Isæus, M. 2004. Factors structuring Fucus communities at open and complex coastlines in the Baltic sea. Department of Botany, Stockholm University, Stockholm.Johnston, A., Fink, D., Reynolds, M.D., Hochachka, 700 W.M., Sullivan, B.L., Bruns, N.E., Hallstein, E., Merrifield, M.S., Matsumoto, 701 S., and Kelling, S. 2015. Abundance models improve spatial and temporal 702 prioritization of conservation resources. Ecol. Appl. 25: 1749-1756. 
Juntunen, T., Vanhatalo, J., Peltonen, H. and Mäntyniemi, S. 2012. Bayesian spatial multispecies modelling to assess pelagic fish stocks from acoustic- and trawlsurvey data. ICES J. Mar. Sci. 69: 95-104.

Kallasvuo, M. 2010. Coastal environmental gradients. Key to reproduction habitat mapping of freshwater fish in the Baltic Sea [online]. Ph.D. thesis, University of Helsinki. Available from http://urn.fi/URN:ISBN:978-952-10-6392-3.

Kjellman, J., Lappalainen, J., Urho, L., and Hudd, R. 2003. Early determination of perch and pikeperch recruitment in the northern Baltic sea. Hydrobiologia. 495: 181-191.

Kuikka, S., Vanhatalo, J., Pulkkinen, H., Mäntyniemi, S., and Corander, J. 2014. Experiences in Bayesian inference in Baltic Salmon management. Stat. Sci. 29: 42-49.

Lappalainen, J., Dörner, H., and Wysujack K. 2003. Reproduction biology of pikeperch (Sander lucioperca (L.)) - a review. Ecol. Freshwat. Fish 12: 95-106.

Latimer, A.M., Wu, S., Gelfand, A.E., and Silander, J.A. 2006. Building statistical models to analyze species distributions. Ecol. Appl. 16: 33-50.

Lehtonen, H., Hansson, S., and Winkler, H. 1996. Biology and exploitation of pikeperch, Stizostedion lucioperca (L.), in the Baltic Sea. Ann. Zool. Fennici. 33: 525-535.

Lindén, A., and Mäntyniemi, S. 2011. Using the negative binomial distribution to model overdispersion in ecological count data. Ecology 92(7): 1414-1421.

Lipcius, R.N., Eggleston, D.B., Schreiber, S.J., Seitz, R.D., Shen, J., Sisson, M., Stockhausen, W.T., and Wang, H.V. 2008. Importance of metapopulation connectivity to restocking and restoration of marine species. Rev. Fish. Sci. 16(1-3): 101-110. doi: 10.1080/10641260701812574. 
Miller, T.J., Crowder, L.B., Rice, J.A., and Marschall, E.A. 1988. Larval size and recruitment mechanisms in fishes: Toward a conceptual framework. Can. J. Fish. Aquat. Sci. 45: 1657-1670.

Myers, R.A. 1998. When do environment-recruitment correlations work? Rev. Fish Biol. Fisher. 8: 285-305.

Parmanne, R., and Sjöblom, V. 1988. The abundance of spring spawning Baltic herring larvae in the seas around Finland in 1982 and 1983, zooplankton abundance and the herring year-class strength. Finnish Fish. Res. 7: 1-11.

Parmanne, R., Rechlin, O., and Sjöstrand, B. 1994. Status and future of herring and sprat stocks in the Baltic Sea. Dana 10: 29-59.

Pekcan-Hekim, Z., Urho, L., Auvinen, H., Heikinheimo, O., Lappalainen, J., Raitaniemi, J., and Söderkultalahti, P. 2011. Climate warming and pikeperch year-class catches in the Baltic Sea. Ambio. 40(5): 447-456. doi: 10.1007/s13280-011-0143-7.

Plate, T.A. 1999. Accuracy versus interpretability in flexible modelling: Implementing a tradeoff using gaussian process models. Behaviourmetrika 26: 29-50.

Rasmussen, C.E. 2004. Gaussian processes for machine learning. In Machine learning. Edited by O. Bousquet. Springer-Verlag, Berlin, Heidenberg. pp. 33-71.

Rasmussen, C.E., and Williams, C.K.I. 2006. Gaussian processes for machine learning. The MIT Press, Massachusetts, USA.

Seitz, R.D., Wennhage, H., Bergström, U., Lipcius, R.N., and Ysebaert, T. 2014. Ecological value of coastal habitats for commercially and ecologically important species. ICES J. Mar. Sci. 71(3): 648-665. doi: 10.1093/icesjms/fst152. 
Shelton, A.O., Thorson, J.T., Ward, E.J., and Feist, B.E. 2014. Spatial semiparametric models improve estimates of species abundance and distribution. Can. J. Fish. Aquat. Sci. 71: 1655-1666. doi:10.1139/cjfas-2013-0508

Shpilev, H., Ojaveer, E., and Lankov, A. 2005. Smelt (Osmerus eperlanus L.) in the Baltic Sea. Proc. Estonian Acad. Sci. Biol. Ecol. 54: 230-241.

Simpson, D.P.; Rue, H., Martins, T.G., Riebler, A., and Sørbye, S.H. 2015. Penalising model component complexity: A principled, practical approach to constructing priors [online]. Available from: arXiv:1403.4630v4

Sjöblom, V., and Parmanne, R. 1978. The vertical distribution of Baltic herring larvae (Clupea harengus L.) in the Gulf of Finland. Finnish Fish. Res. 2: 5-18.

Snickars, M., Sundblad, G., Sandström, A., Ljunggren, L., Bergström, U., Johansson, G., and Mattila, J. 2010. Habitat selectivity of substrate-spawning fish: Modelling requirements for the Eurasian perch Perca fluviatilis. Mar. Ecol. Prog. Ser. 398: $235-243$.

Söderkultalahti, P. 2015. Ammattikalastus merellä (Commercial fisheries in the northern Baltic Sea) [online]. Natural Resources Institute Finland. Available from: http://stat.luke.fi/ammattikalastus-merell\%C3\%A4-2014_fi 16.5.2016.

Sundblad, G., and Bergström, U. 2014. Shoreline development and degradation of coastal fish reproduction habitats. Ambio. 43: 1020-1028. doi: 10.1007/s13280-014$0522-y$.

Sundblad, G., Bergström, U., Sandström, A., and Eklöv, P. 2014. Nursery habitat availability limits adult stock sizes of predatory coastal fish. ICES J. Mar. Sci. 71: 672-680. doi: 10.1093/icesjms/fst056. 
Thorson, J.T., Shelton, A.O., Ward, E.J., and Skaug, H.J. 2015. Geostatistical deltageneralized linear mixed models improve precision for estimated abundance indices for West Coast groundfishes. ICES J. Mar. Sci. 72: 1297-1310. doi:10.1093/icesjms/fst176

Urho, L. 1996: Identification of perch (Perca fluviatilis), pikeperch (Stizostedion lucioperca) and ruffe (Gymnocephalus cernuus) larvae. Ann. Zool. Fenn. 33: 658-667

Urho, L. 2002: Characters of larvae - what are they? Folia Zool. 51: 161-186.

Urho, L., and Hildén, M. 1990. Distribution patterns of Baltic herring larvae, Clupea harengus L., in the coastal waters off Helsinki, Finland. J. Plankton Res. 12(1): 41-54. doi: 10.1093/plankt/12.1.41.

Urho, L., Hildén, M., and Hudd, R. 1990. Fish reproduction and the impact of acidification in the Kyrönjoki river estuary in the Baltic Sea. Environ. Biol. Fishes. 27: 273283.

Vanhatalo, J. and Vehtari, A. 2008. Modelling local and lobal phenomena with sparse Gaussian processes [online]. Proceedings of the 24th Conference on Uncertainty in Artificial Intelligence, Helsinki. Available at: https://arxiv.org/ftp/arxiv/papers/1206/1206.3290.pdf

Vanhatalo, J., Veneranta, L., and Hudd, R. 2012. Species distribution modeling with Gaussian processes: A case study with the youngest stages of sea spawning whitefish (Coregonus lavaretus L. s.1.) larvae. Ecol. Model. 228: 49-58.

Vanhatalo, J., Riihimäki, J., Hartikainen, J., Jylänki, P., Tolvanen, V., and Vehtari, A. 2013. GPstuff: Bayesian modeling with Gaussian processes. J. Mach. Learn. Res. 14: 1175-1179. doi: http://arxiv.org/pdf/1206.5754.pdf. 
793 Vanhatalo, J., Hosack, G. and Sweatman, H. (In press). Spatio-temporal progression of outbreaks of the crown-ofthorns starfish on the Great Barrier Reef, 1985-2014.

795 J. Appl. Ecol.

796

Vehtari, A., and Ojanen, J. 2012. A survey of Bayesian predictive methods for model assessment, selection and comparison. Stat. Surv. 6: 142-228.

798 Veneranta, L., Urho, L., Lappalainen, A., and Kallasvuo, M. 2011. Turbidity characterizes 799 the reproduction areas of pikeperch (Sander lucioperca $(\mathrm{L})$.$) in the northern$

800 Baltic Sea. Estuar. Coast. Shelf Sci. 95: 199-206.

801 Voipio, A. 1981. The Baltic Sea. Elsevier, Amsterdam, the Netherlands.

802 


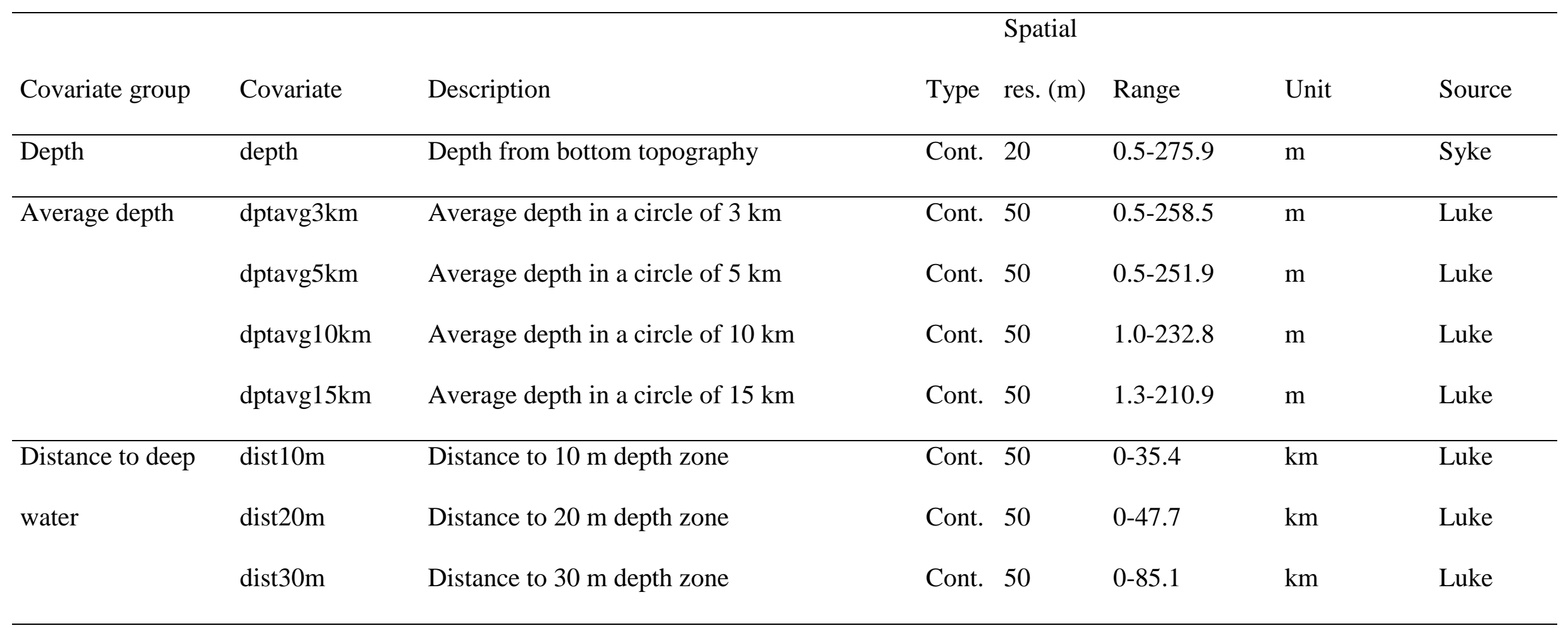




\begin{tabular}{|c|c|c|c|c|c|c|}
\hline Influence of rivers & river & \\
\hline \multirow[t]{3}{*}{ Shoreline density } & shoreline $3 \mathrm{~km}$ & Shoreline length in a circle of $3 \mathrm{~km}$ & Cont. 50 & $0-10.3$ & $\mathrm{~m} / \mathrm{km}^{2}$ & Luke \\
\hline & shoreline $5 \mathrm{~km}$ & Shoreline length in a circle of $5 \mathrm{~km}$ & Cont. 50 & $0-7.5$ & $\mathrm{~m} / \mathrm{km}^{2}$ & Luke \\
\hline & shoreline $15 \mathrm{~km}$ & Shoreline length in a circle of $15 \mathrm{~km}$ & Cont. 50 & $0-4.3$ & $\mathrm{~m} / \mathrm{km}^{2}$ & Luke \\
\hline Exposure & exposure & Log10 of wave exposure & Cont. 25 & $2.1-6.1$ & $\log 10\left(\mathrm{~m}^{2} \mathrm{~s}^{-1}\right)$ & Aquabiota \\
\hline
\end{tabular}



mean $m$ and variance $\tau$, Student ${ }_{+}-t(v, m, s)$ is the Student- $t$ distribution restricted on non-

809 zero values with $v$ degrees of freedom, location $m$, and scale $s$, and $\operatorname{Gamma}(\alpha, \beta)$ is the

810 Gamma distribution with shape $\alpha$ and inverse scale $\beta$ (Gelman et al. 2013).

811

Parameter

Mean log density (intercept), $\alpha$

Over dispersion, $\mathrm{r}$

Variance of spatio-temporal component $\sigma_{\phi}^{2}$

Longitudinal length scale of spatio-temporal component, $l_{1}$

Latitudinal length scale of spatio-temporal component, $\mathrm{l}_{2}$

Temporal length scale of spatio-temporal component, $l_{3}$

Variance of spatial component $\sigma_{\rho}^{2}$

Longitudinal length scale of spatial component, $\lambda_{1}$

Latitudinal length scale of spatial component, $\lambda_{2}$

Variance of the interaction term, $\sigma_{h}^{2}$

Weights along covariates in the interaction term $\left\{w_{d}\right\}_{d=1}^{D}$

Variance parameters of the additive functions,

$\left\{\sigma_{g_{d}, 0}^{2}, \sigma_{g_{d}}^{2}\right\}_{d=1}^{D}$

\section{Prior}

$N(0,10)$

$\operatorname{Gamma}(2,0.1)$

$p\left(\sigma_{\phi}^{2}\right) \propto 1 / \sigma_{\phi}^{2}$

$w_{d} \sim$ Student $t_{+}-t(4,0,100)$

$w_{d} \sim$ Student $t_{+}-t(4,0,100)$

$w_{d} \sim$ Student ${ }_{+}-t(4,0,1)$

$p\left(\sigma_{\rho}^{2}\right) \propto 1 / \sigma_{\rho}^{2}$

$w_{d} \sim$ Student ${ }_{+}-t(4,0,100)$

$w_{d} \sim$ Student $t_{+}-t(4,0,100)$

$p\left(\sigma_{h}^{2}\right) \propto 1 / \sigma_{h}^{2}$

$w_{d} \sim$ Student $t_{+}-t(4,0,1)$

$p\left(\sigma_{g_{d}, 0}^{2}\right) \propto 1 / \sigma_{g_{d}, 0}^{2}$

$p\left(\sigma_{g_{d}}^{2}\right) \propto 1 / \sigma_{g_{d}}^{2}$

812 
813 Table 3 . The posterior median and central 95\% credible interval of the overdispersion

814 parameter, variance of the interaction term and parameters of the spatial and spatio-temporal 815 covariance functions.

816

\begin{tabular}{|c|c|c|c|c|}
\hline & Perch & Pikeperch & Baltic herring & Smelt \\
\hline Mean log density & -3.79 & -6.59 & -2.77 & -3.32 \\
\hline (intercept), $\alpha$ & $(-6.19,-1.40)$ & $(-9.16,-4.02)$ & $(-4.67,-0.87)$ & $(-5.73,0.90)$ \\
\hline \multirow[t]{2}{*}{ Over dispersion, $r$} & 1.18 & 11.48 & 1.79 & 2.45 \\
\hline & $(0.80,2.25)$ & $(2.53,47.97)$ & $(1.26,3.02)$ & $(1.28,6.84)$ \\
\hline Variance of spatio- & 6.69 & 0.29 & 2.39 & 2.36 \\
\hline temporal component $\sigma_{\phi}^{2}$ & $(4.53,11.08)$ & $(0.01,1.47)$ & $(1.53,3.80)$ & $(0.38,5.23)$ \\
\hline Longitudinal length scale & 17.80 & 5.03 & 12.21 & 10.25 \\
\hline of spatio-temporal & $(10.47,31.47)$ & $(0.42,26.87)$ & $(6.76,24.40)$ & $(4.60,28.97)$ \\
\hline \multicolumn{5}{|l|}{ component, $\mathrm{l}_{1}$} \\
\hline Latitudinal length scale of & 34.11 & 6.88 & 16.93 & 8.53 \\
\hline spatio-temporal & $(17.78,75.70)$ & $(0.14,37.91)$ & $(9.47,33.13)$ & $(2.53,33.58)$ \\
\hline \multicolumn{5}{|l|}{ component, $\mathrm{l}_{2}$} \\
\hline Temporal length scale of & 0.88 & 0.70 & 0.61 & 0.66 \\
\hline spatio-temporal & $(0.03,2.73)$ & $(0.01,3.71)$ & $(0.03,2.26)$ & $(0.05,3.48)$ \\
\hline \multicolumn{5}{|l|}{ component, $l_{3}$} \\
\hline Variance of spatial & 0.07 & 6.10 & 0.03 & 1.64 \\
\hline component $\sigma_{\rho}^{2}$ & $(0.00,1.02)$ & $(3.43,13.52)$ & $(0.00,0.42)$ & $(0.00,4.17)$ \\
\hline Longitudinal length scale & 7.34 & 17.10 & 7.59 & 10.05 \\
\hline of spatial component, $\lambda_{1}$ & $(0.04,36.21)$ & $(9.60,35.64)$ & $(0.57,32.89)$ & $(1.76,31.94)$ \\
\hline
\end{tabular}




\begin{tabular}{lllll}
\hline Latitudinal length scale of & 7.58 & 18.67 & 8.56 & 14.90 \\
spatial component, $\lambda_{2}$ & $(0.15,31.39)$ & $(8.70,46.88)$ & $(0.29,42.25)$ & $(1.83,49.51)$ \\
Variance of the interaction & 0.44 & 0.19 & 0.09 & 0.47 \\
term, $\sigma_{h}^{2}$ & $(0.01,2.24)$ & $(0.00,2.28)$ & $(0.00,0.49)$ & $(0.01,3.41)$
\end{tabular}

817 
818 Table 4. Expected total number of larvae (95\% credible interval), percentage of the studied

819 water area suitable for larvae (suitable areas) and producing $80 \%$ of larvae (important areas)

820 by species and sea area ( $\mathrm{I}=$ Bothnian Bay; II = Quarken area; III = Bothnian Sea; IV =

821 Archipelago Sea; V = Gulf of Finland). The sea areas sum up to the total study area.

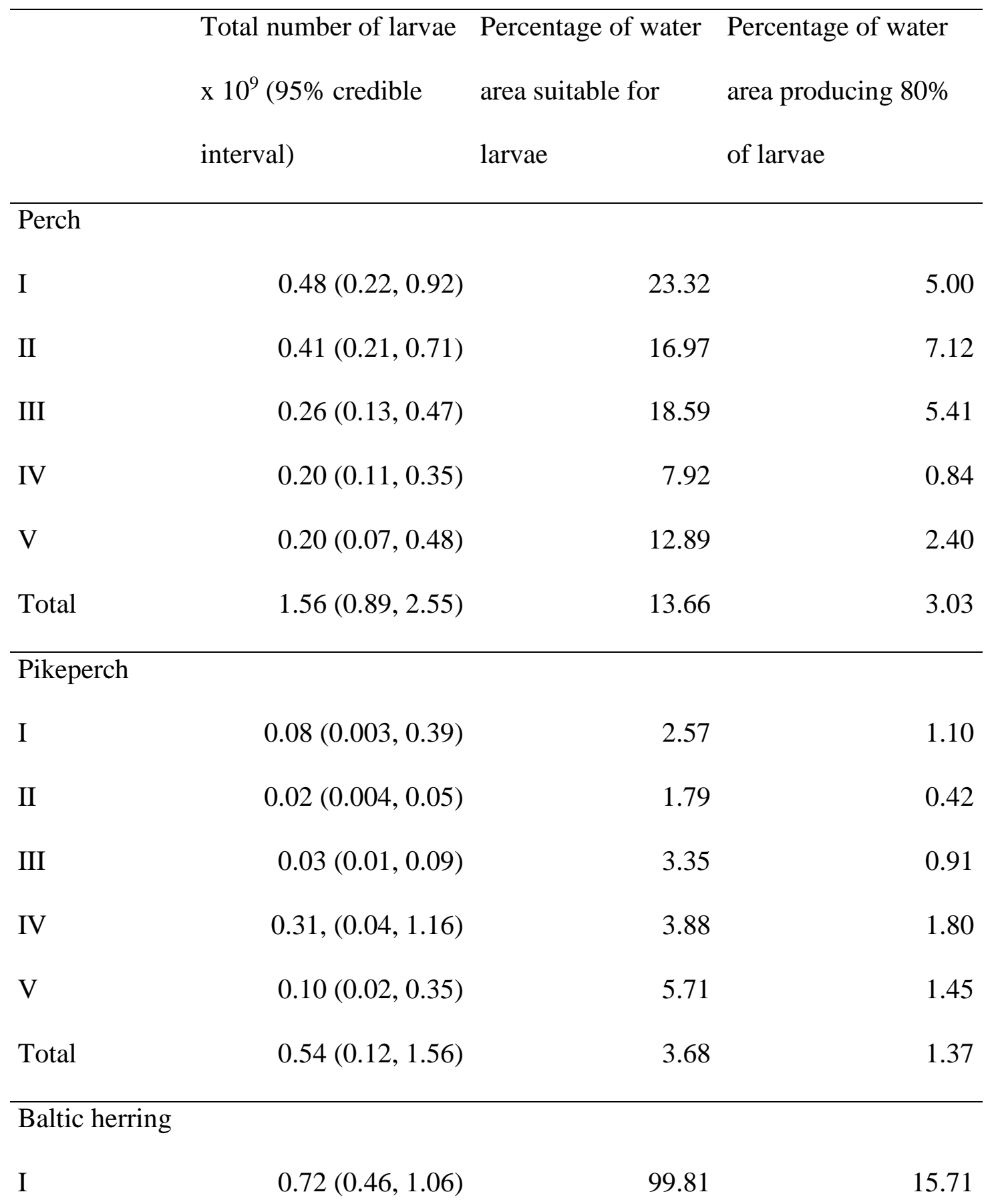




\begin{tabular}{lccc} 
II & $0.50(0.34,0.70)$ & 99.87 & 16.48 \\
III & $0.57(0.41,0.78)$ & 99.79 & 24.71 \\
IV & $4.93(3.01,7.63)$ & 99.87 & 74.07 \\
V & $2.00(1.12,3.31)$ & 99.53 & 78.90 \\
Total & $8.72(5.65,12.86)$ & 99.79 & 52.89 \\
\hline Smelt & & & \\
I & $3.30(1.22,7.25)$ & 70.88 & 12.12 \\
II & $0.79(0.44,1.32)$ & 25.49 & 7.43 \\
III & $0.74(0.23,1.82)$ & 22.27 & 4.62 \\
IV & $0.49(0.18,1.06)$ & 5.91 & 1.12 \\
V & $0.58(0.20,1.35)$ & 12.34 & 2.78 \\
Total & $5.91(2.88,10.81)$ & 22.50 & 4.44 \\
\hline
\end{tabular}


824 Figure legends

825

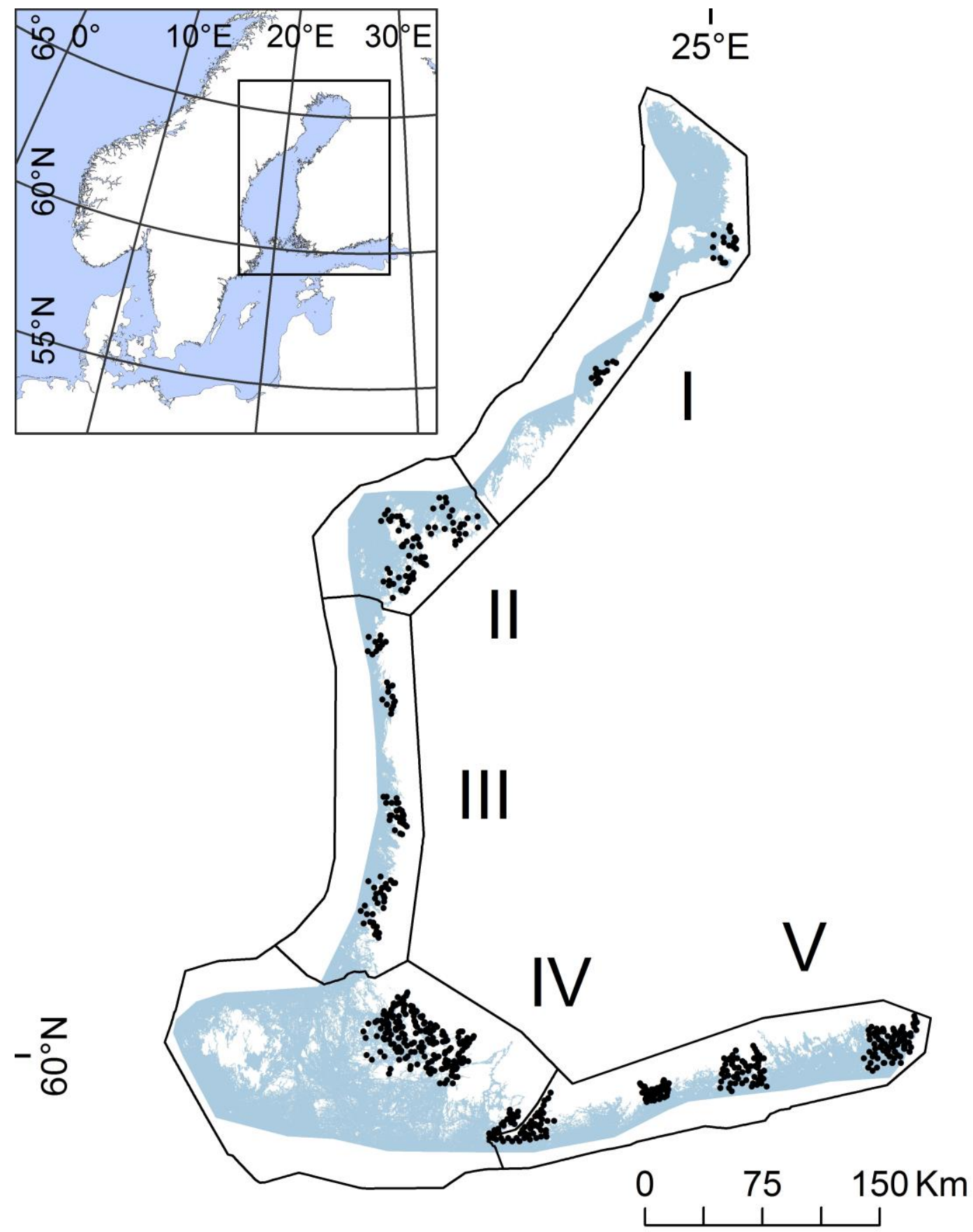

826

827 Figure 1. The study area (grey), larval fish survey sites (black dots) and the sea area divisions

828 (I = Bothnian Bay; II = Quarken area; III = Bothnian Sea; IV = Archipelago Sea; V = Gulf of 829 Finland). 

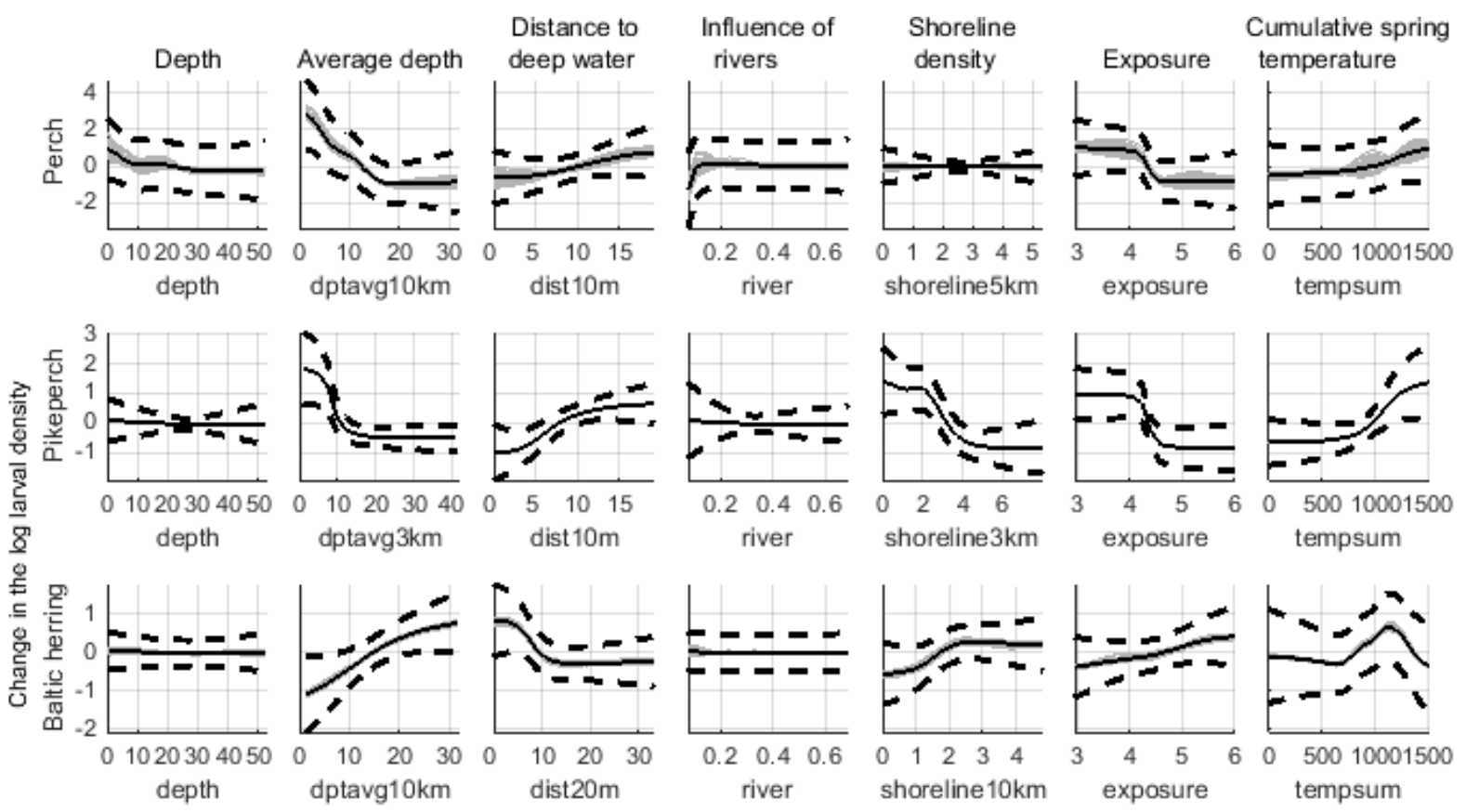

831
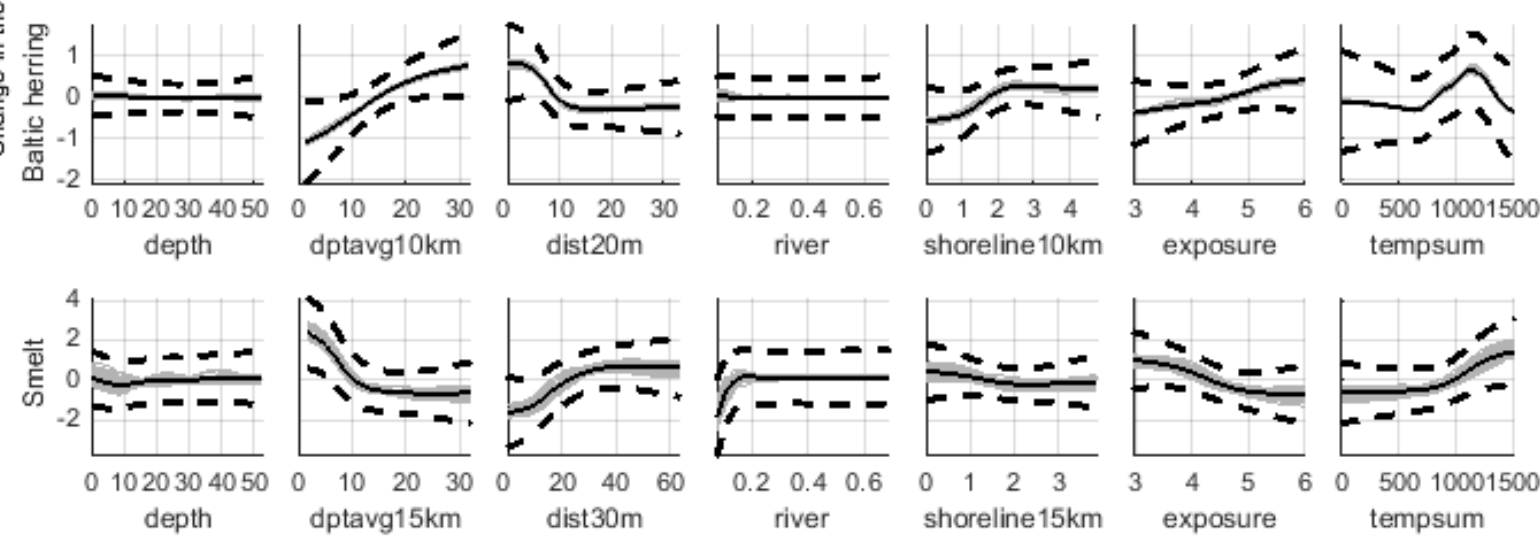

832 Figure 2. The response of log-transformed larval density along environmental covariates,

833 shown for the four study species. A change in the log density by one unit corresponds to a

834 2.7-fold increase in the density. The solid and dashed black lines describe, respectively, the

835 average response and the $95 \%$ credible interval over all data points. The grey lines show the

836 expected response in 50 randomly chosen locations. 

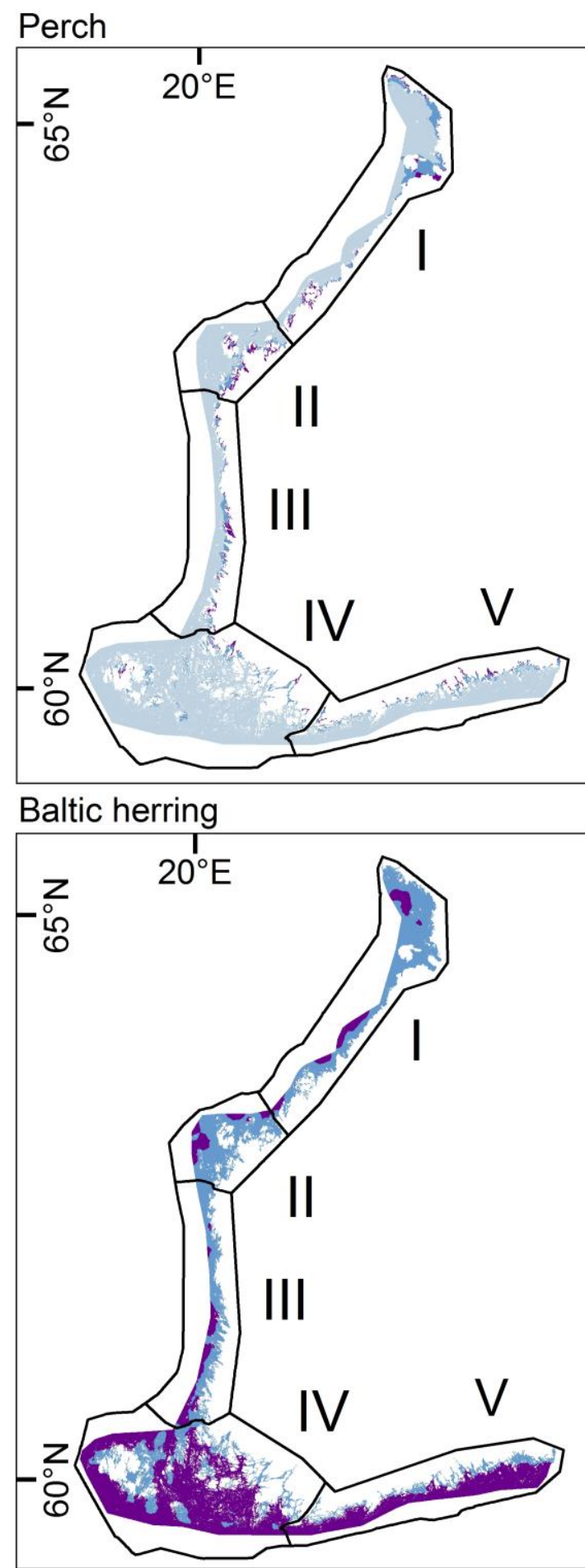

Not suitable $\square$ Suitable
Pikeperch

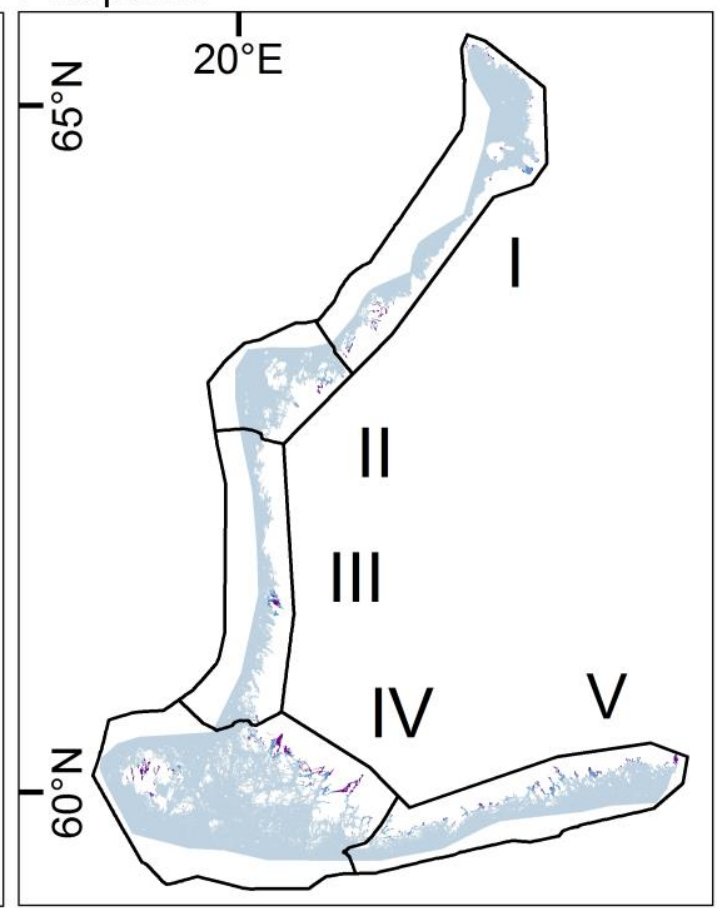

\section{Smelt}

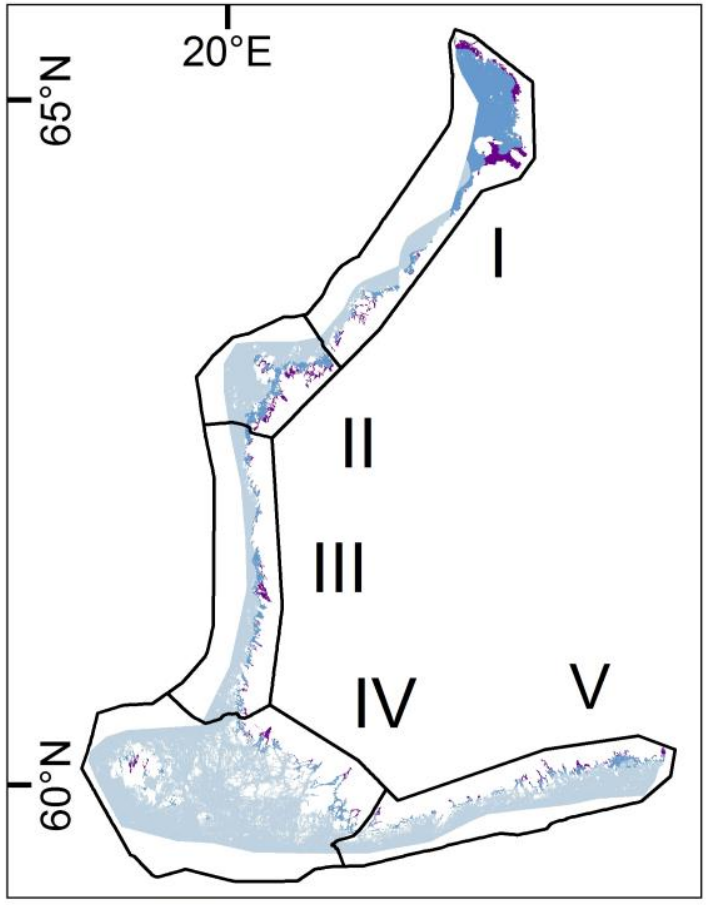

Important

Figure 3. Predicted larval density maps of perch, pikeperch, Baltic herring, and smelt

840 classified into three classes: not suitable (no larvae expected), suitable (expected area 
841 producing lowest $20 \%$ of all larvae), and important (the smallest expected area producing

$84280 \%$ of all larvae).

843

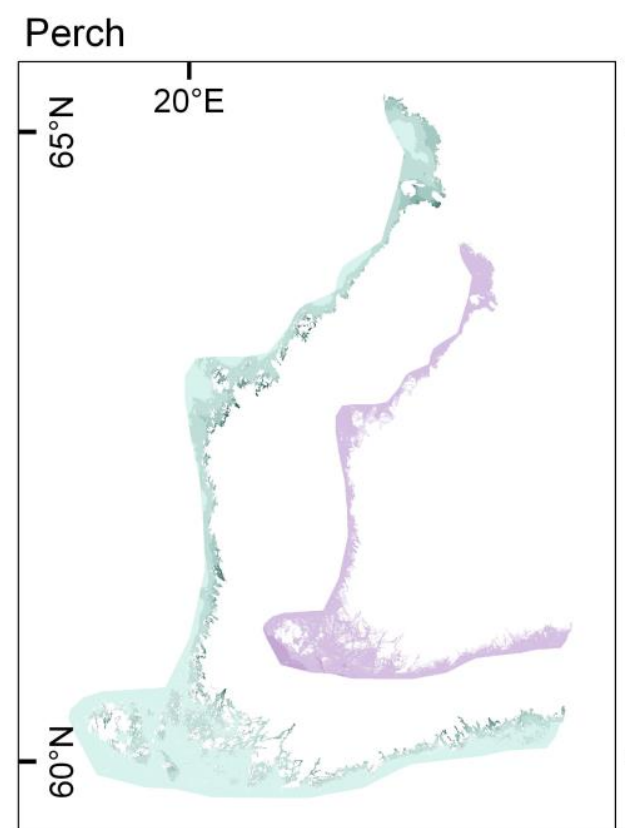

Pikeperch

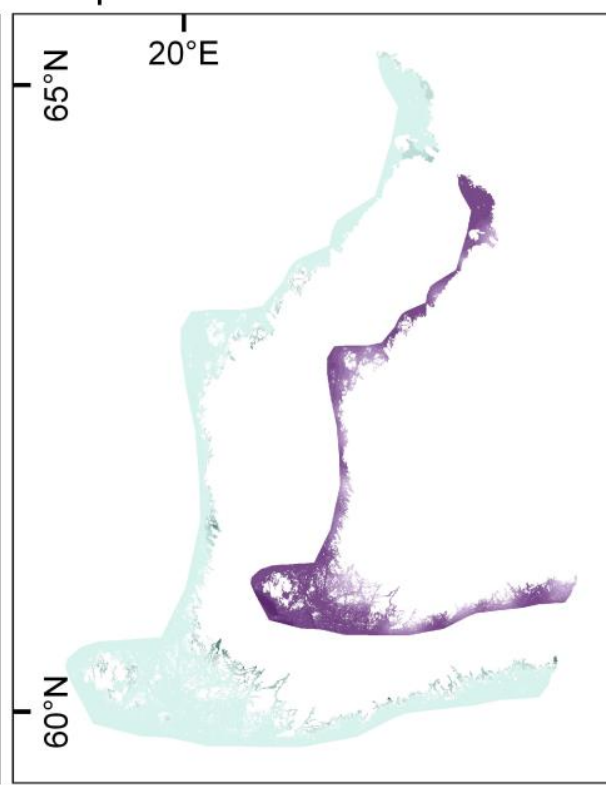

Density larvae $/ \mathrm{m}^{3}$

$\square 0.00009-0.0009$

$0.0009-0.007$

$0.007-0.05$

$\square 0.05-0.1$

$\square 0.1-0.2$

$\square .2-0.4$

$\square 0.4-0.6$

$\square 0.6-0.9$

$\square .9-1.6$

$\square 1.6-12.0$

Baltic herring

Smelt
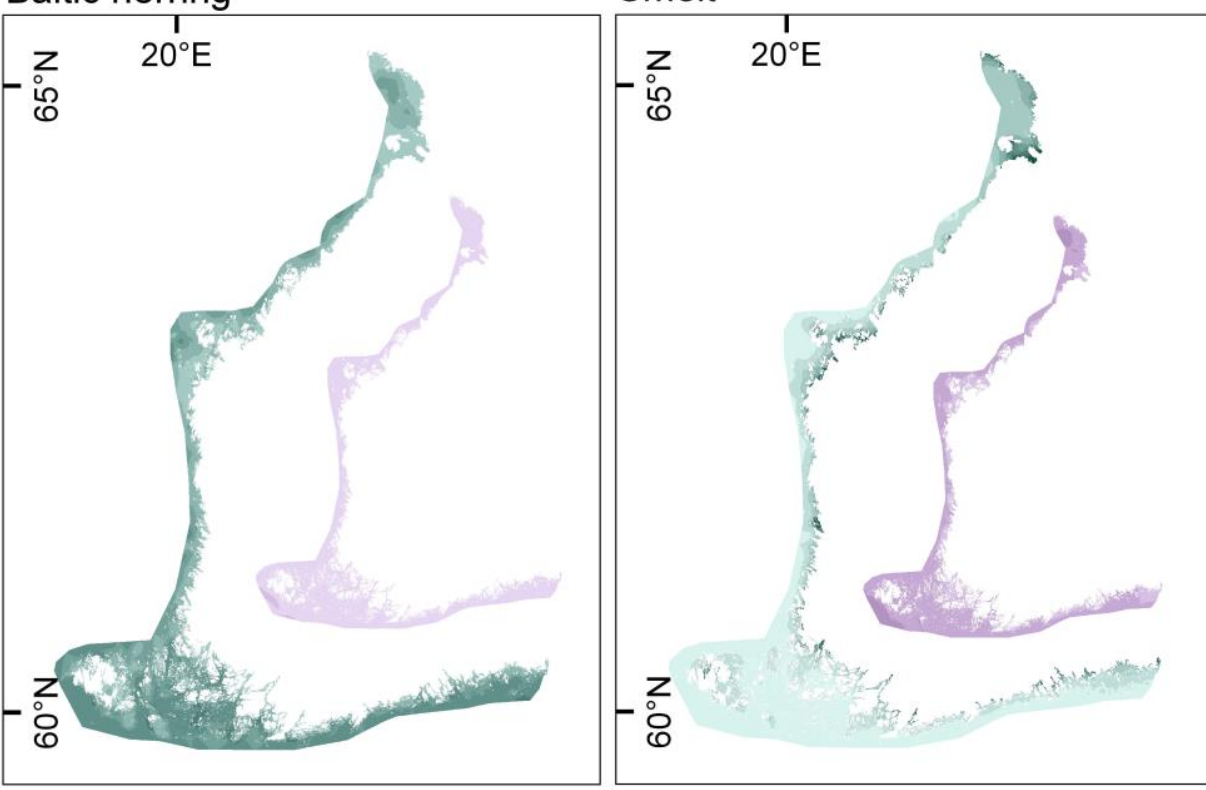

Coefficient of variation

$0.3-1.0$

$\square$ 1.0-2.5

$2.5-5.0$

$\square .0-7.5$

$7.5-10.0$

$\square 10.0$ - 12.5

$\square 12.50-15.0$

$\square 15.0-20.0$

20.0-25.0

$\square 25.0-30.9$

844

845 Figure 4. The posterior predictive median (larger maps) and coefficient of variation (smaller

846 maps inside the former) of the larval density of perch, pikeperch, Baltic herring, and smelt. 
Computational details

852

We applied Bayes' theorem and calculated the posterior distribution of the

covariance function parameters and the latent variables (latent function values corresponding to the observation locations) using the Matlab toolbox GPstuff (Vanhatalo et al. 2013). First, we used the expectation propagation (EP) algorithm to search for the (approximate) maximum a posterior estimate of the covariance function parameters and a Gaussian approximation for the latent variables (see Rasmussen and Williams 2006 and Vanhatalo et al. 2010 for details). EP is a fast approximate algorithm, and its accuracy has been shown to be good in the models we were interested in here (Vanhatalo et al. 2010). Hence, it provides an efficient tool for early "model exploration". After this, we conducted a Markov chain Monte Carlo (MCMC) simulation for the full posterior of covariance function parameters and

863 latent variables by alternating the sampling from conditional distribution of latent variables given covariance function parameters, and vice versa. We used elliptical slice sampling

865 (Murray et al. 2010) for the latent variables and slice sampling (Neal 2003) for the parameters

866 of covariance functions. We sampled 20000 samples, from which the first 1000 were

867 removed as burn-in. The convergence was checked by the potential scale reduction factor

868 (Gelman et al. 2013). After, this, we thinned the chain to obtain approximately 200

869 independent samples with which the final results were calculated.

871 area. Since the spatio-temporal random effects describe annual changes in larval abundance,

872 we predicted the larval density in grid cells using only the temporally constant terms; that is, 
873 we predicted $\tilde{f}\left(s, x_{s}\right)=\alpha+\sum_{d=1}^{D} g_{d}\left(x_{s, d}\right)+h\left(x_{s}\right)+\rho(s)$ in each grid cell and used this to

874 represent the average log larval density between 2007 and 2014. This corresponds to

875 effectively filtering out the temporal changes in the density and can be calculated

876 straightforwardly as presented by Rasmussen and Williams (2006) and Vanhatalo (2010).

877

We calculated the total larval density in an area, $A$, by a sum of densities in grid

878 cells in that area; that is, $I_{\text {tot }}=\sum_{s_{i} \in A} e^{\tilde{f}\left(s_{i}, x_{s_{i}}\right)}$, where $s_{i}$ is the coordinate of cell $i$. Sampling

879 from the posterior distribution of $I_{\text {tot }}$ would require first sampling from the joint posterior of

$880 f$ in all grid cells, during which we would need to form the (posterior) covariance matrix of

$881 \tilde{f}$. Since we had over 12 million grid cells in the whole study area, this is infeasible.

882 However, we can calculate the posterior mean and variance of the total density exactly; the

883 former is the sum of expectations over grid cells, $E\left[I_{\text {tot }}\right]=\sum_{s_{i} \in A} E\left[e^{\tilde{f}\left(s_{i}, x_{s_{i}}\right)}\right]$, and the latter

884 is the sum of all elements in the covariance matrix $\operatorname{Var}\left[I_{\text {tot }}\right]=$

$885 \sum_{s_{i}, s_{j} \in A} \operatorname{Cov}\left[e^{\tilde{f}\left(s_{i}, x_{s_{i}}\right)}, e^{\tilde{f}\left(s_{j}, x_{s_{j}}\right)}\right]$. Both summaries can be calculated sequentially or the

886 computation can be parallelized and does not involve forming the full covariance matrix.

887 After solving the mean and variance, we approximated the posterior distribution for the total

888 density by a log-Gaussian distribution (Kelsall and Wakefield 2002). In order to speed up the

889 calculations, we used the EP approximation for the posterior when calculating the posterior

890 for the total density. The error from using EP here is negligible, since it provided a good

891 match with the MCMC approximation for the posterior distributions of the latent variables. expected, zero-centered change in the log density along each covariate. That is, we calculated

894 the posterior of $\left.\tilde{f}\left(s, t, x_{s}\right)\right|_{k}=\left.f\left(s, t, x_{s}\right)\right|_{k}-\left.\bar{f}\left(s, t, x_{s}\right)\right|_{k}$ along covariate $k$ where

$\left.895 f\left(s, t, x_{s}\right)\right|_{k}$ is a function of the $k$ th covariate only when all other covariates are fixed at their 
896 values at location $s$ and $\left.\bar{f}\left(s, t, x_{s}\right)\right|_{k}=\frac{1}{u_{k}-l_{k}} \int_{l_{k}}^{u_{k}} f\left(s, t, x_{s}\right) d x_{s, k}$ is the mean of the function 897 over interval $\left[u_{k}, l_{k}\right]$ along covariate $k$ at that location. We approximated the mean of the 898 function by the arithmetic mean over $M=20$ equally spaced values along covariate $k$.

899 Moreover, we calculated the expected response for 50 random locations in order to visualize 900 the effect of the interaction term.

901

902 Comparison of models with and without spatial and spatio-temporal random effects

903

904

In order to assess the importance of the spatial and spatio-temporal random

905

effects from the posterior predictive point of view we compared our model with models that

906

were otherwise similar but did not include the random effects. We assessed the model

907 performance by using the approximate leave-one-out cross-validation (Vehtari et al. 2014)

908 with log predictive density diagnostics (Vehtari and Ojanen 2012)

909

$$
\sum_{i=1}^{n} \ln p\left(y_{i} \mid x_{i}, s_{i}, y_{\backslash i}, x_{\backslash i}, s_{\backslash i}\right),
$$

910

where $y_{\backslash i}, s_{\backslash i}$ and $x_{\backslash i}$ collect all observations, locations and covariates except those related to

911 the $i$ th data point and $p\left(y_{i} \mid x_{i}, s_{i}, y_{\backslash i}, x_{\backslash i}, s_{\backslash i}\right)$ denotes the posterior predictive density of

912 the $i$ th observation. A larger log predictive density indicated a better model. The log

913 predictive density statistics are summarized in Table A1.

914

915 References

916 
917

918

919

920

921

922

923

924

925

926

927

928

929

930

931

932

933

934

935

936

937

938

Gelman, A., Carlin, J., Stern, H., Dunson, D., Vehtari, A., and Rubin. D. 2013. Bayesian Data Analysis, Third Edition. Chapman \& Hall / CRC Texts in Statistical Science, Miami, USA.

Kelsall, J., and Wakefield, J. 2002. Modeling spatial variation in disease risk: A geostatistical approach. J. Amer. Statist. Assoc. 97: 692-701.

Murray, I., Adams, R.P., and MacKay, D.J.C. 2010. Elliptical slice sampling. J. Mach. Learn. Res.: Workshop and conference proceedings 9:541-548.

Neal, R.M. 2003. Slice sampling. Ann. Stat. 31: 705-767.

Rasmussen, C.E., and Williams, C.K.I. 2006. Gaussian Processes for Machine Learning. The MIT Press, Massachusetts, USA.

Vanhatalo, J. 2010. Speeding Up the Inference in Gaussian Process Models. PhD Thesis, Aalto University, School of Science and Technology.

Vanhatalo, J., Pietiläinen, V., and Vehtari, A. 2010. Approximate inference for disease mapping with sparse Gaussian processes. Stat. Med. 9: 1580-1607.

Vanhatalo, J., Riihimäki, J., Hartikainen, J., Jylänki, P., Tolvanen, V., and Vehtari A. 2013. GPstuff: Bayesian Modeling with Gaussian Processes. J. Mach. Learn. Res. 14: 1175-1179.

Vehtari, A., and Ojanen, J. 2012. A survey of Bayesian predictive methods for model assessment, selection and comparison. Stat. Surv. 6: 142-228.

Vehtari, A., Tolvanen, V., Mononen, T., and Winther, O. 2014. Bayesian leave-one-out cross-validation approximations for Gaussian latent variable models. arXiv:1412.7461v1

939 
940 Table A1. The leave-one-out cross-validation log predictive densities (LPD) and the posterior

941 mode of the overdispersion parameter $(\hat{r})$ of the used models and otherwise similar models

942 from which the spatial and spatio-temporal random effects have been omitted (the higher

943 values are better).

944

\begin{tabular}{lllll}
\hline & Perch & Pikeperch & Baltic herring & Smelt \\
& LPD $(\hat{r})$ & LPD $(\hat{r})$ & LPD $(\hat{r})$ & LPD $(\hat{r})$ \\
\hline Full model & $-981.91(1.18)$ & $-504.15(14.24)$ & $-1296.17(1.76)$ & $-1130.33(2.44)$ \\
Full model $-\phi(s, t)$ & $-981.87(1.18)$ & $-507.80(13.84)$ & $-1296.08(1.77)$ & $-1132.70(2.14)$ \\
Full model $-\rho(s)$ & $-1013.69(0.84)$ & $-504.50(9.65)$ & $-1319.54(1.18)$ & $-1136.20(1.78)$ \\
Full model $-\rho(s)-\phi(s, t)$ & $-1058.89(0.50)$ & $-574.29(0.82)$ & $-1367.01(1.17)$ & $-1178.05(0.94)$ \\
\hline
\end{tabular}



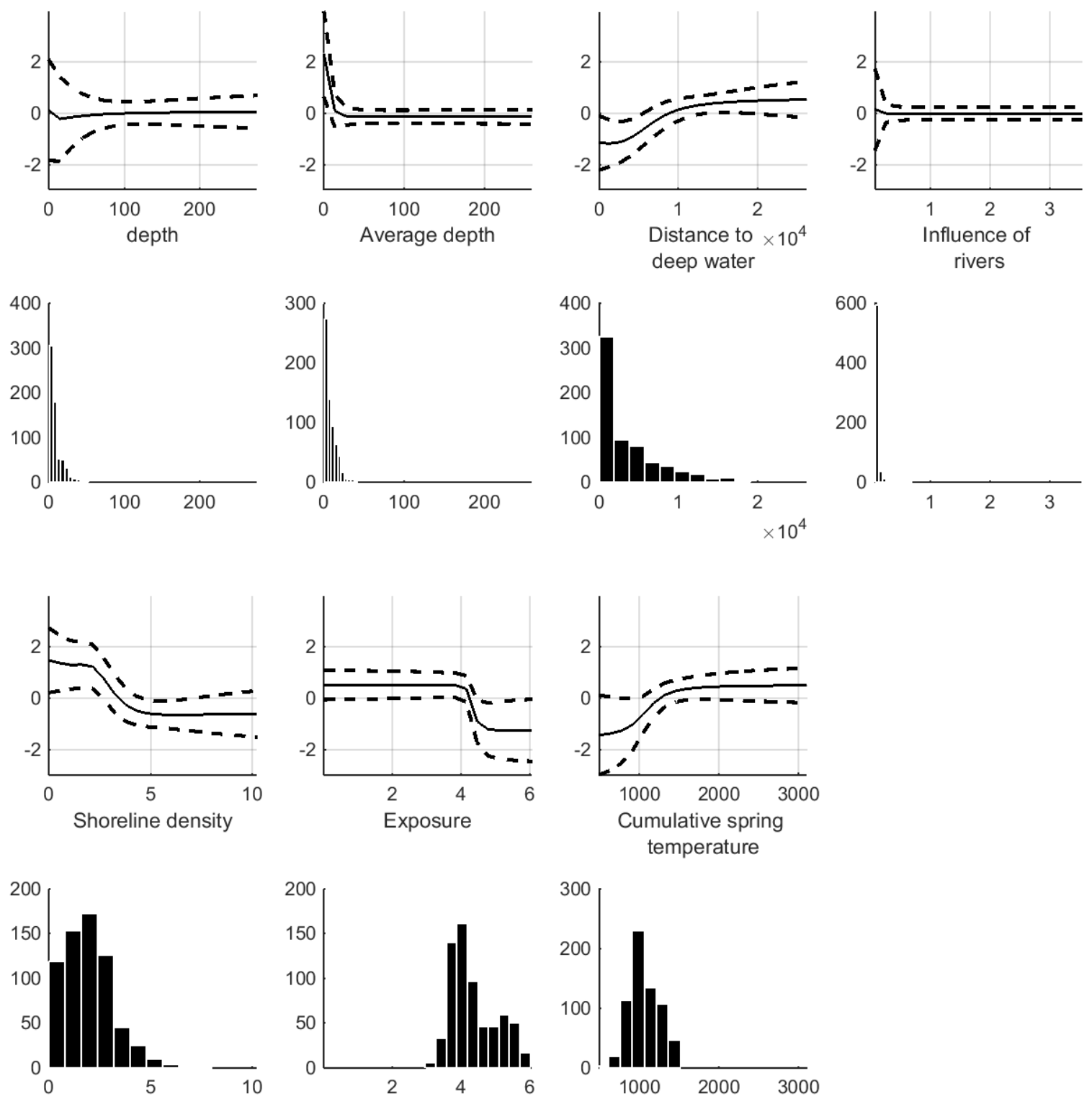

947 Figure A1. The response of log-transformed pikeperch larval density along the environmental

948 covariates within the prediction range of the covariates. The solid and dashed black lines

949 describe, respectively, the average response and the $95 \%$ credible interval. The histograms

950 show the distribution of covariate values in the data. Notice that when extrapolating the

951 prediction stays at the level where the predictive function was at the end of the data range.

952 This behavior is typical for neural network covariance function. With radial covariance

953 functions, such as the squared exponential, the predictive function would approach prior

954 mean (zero) when extrapolating. 